\title{
Functional neuroanatomy of emotions: A meta-analysis
}

\author{
FIONNUALA C. MURPHY, IAN NIMMO-SMITH, and ANDREW D. LAWRENCE \\ MRC Cognition and Brain Sciences Unit, Cambridge, England
}

\begin{abstract}
The application of functional neuroimaging to the study of human emotion has yielded valuable data; however, the conclusions that may be drawn from any one study are limited. We applied novel statistical techniques to the meta-analysis of 106 PET and fMRI studies of human emotion and tested predictions made by key neuroscientific models. The results demonstrated partial support for asymmetry accounts. Greater left-sided activity was observed for approach emotions, whereas neural activity associated with negative/withdrawal emotions was symmetrical. Support was also found for affect program emotion accounts. The activation distributions associated with fear, disgust, and anger differed significantly. These emotions were most consistently associated in activity in regions associated with selective processing deficits when damaged: the amygdala, the insula and globus pallidus, and the lateral orbitofrontal cortex, respectively. In contrast, the distributions for happiness and sadness did not differ. These findings are considered in the context of conceptualizations of the neural correlates of human emotion.
\end{abstract}

The relatively recent introduction of functional neuroimaging (FNI) to the neuroscientific study of mental processes has been accompanied by a surge of interest in the neuroscience of human emotion. Previous research in the field of affective neuroscience relied on lesion methods, pharmacological manipulations, and electrophysiological studies conducted both in laboratory animals and in human volunteers. The results of these studies formed the basis for a number of neuroscientific models of emotion that continue to guide contemporary research in this rapidly growing field. Here, we describe a meta-analysis of relevant FNI studies in order to assess key neuroscientific accounts of human emotion. We begin by describing several single- and multisystem neuroscientific models of emotion that make testable predictions at the level of the central nervous system (CNS).

\section{Single-System Models of Emotion}

One of the most prominent and widely accepted early theories of structure-function relationships is MacLean's $(1949,1952)$ pioneering limbic system theory of emotion, which considered "every variety of affect" to be mediated by a specialized group of brain structures that collectively formed an integrated neural system (albeit with three major subdivisions; MacLean, 1993, 2001). Although the limbic system concept continues to permeate current thinking about how the brain mediates emotion, its validity has been questioned on both anatomical (LeDoux,

This research was supported by the U.K. Medical Research Council (MRC). We thank Matthew Brett for developing the MNI2TAL and TAL2MNI algorithms. Correspondence concerning this article should be addressed to F. C. Murphy, MRC Cognition and Brain Sciences Unit, 15 Chaucer Road, Cambridge CB2 2EF, England (e-mail:fionnuala. murphy@mrc-cbu.cam.ac.uk).
1991; Reiner, 1990) and theoretical (Calder, Lawrence, \& Young, 2001) grounds. Recent studies in the field of affective neuroscience suggest that the limbic system model may no longer be sufficient, at least in its most specific form, and yet the broader concept of a unitary emotion system remains attractive to many investigators (Damasio, 1998; Panksepp, 2000).

An alternative single-system model, and arguably one of the earliest models of emotion lateralization, is the right-hemisphere (RH) hypothesis (Mills, 1912; Sackeim \& Gur, 1978; Schwartz, Davidson, \& Maer, 1975). In its earliest form, this hypothesis highlighted a critical role for the RH in all aspects of emotion processing, including both positive and negative emotions. For example, behavioral studies in humans have shown that emotions are expressed more intensely on the left side of the face (Sackeim \& Gur, 1978) and that RH damage has been associated with impaired recognition of facial expressions of emotion (Mandal, Mohanty, Pandey, \& Mohanty, 1996). It should be noted that not all studies have demonstrated a reliable emotion-RH link (Mandal, Asthana, Tandon, \& Asthana, 1992), and interested readers are referred to the following source for further reading in this area (Borod, Zgaljardic, Tabert, \& Koff, 2001). More recently, several variants of this early hypothesis have begun to emerge. For example, some theorists maintain that the RH may be more specifically involved in the perception and expression of emotion, rather than in its experience, and that posterior regions may be especially important (Adolphs, Damasio, Tranel, \& Damasio, 1996; Borod et al., 1998; Borod et al., 2001; Heller, Nitschke, \& Miller, 1998). Yet other investigators have suggested that the RH is specialized for the processing of highly arousing, unpleasant emotions, such as anger and fear (Adolphs, Russell, \& Tranel, 1999). 
It could be argued that these refinements of the RH hypothesis reflect a more general shift in the way theorists have begun to conceptualize the neural bases of emotion. Indeed, many investigators have begun to move away from thinking in terms of an integrated neural system that codes all emotional processes toward thinking in terms of individual neural systems coding distinct dimensions of emotion or different affect programs. Examples of key dual- and multisystem models of this sort will be detailed below.

\section{Dual-System Models of Emotion}

At a psychological level of explanation, dimensional accounts consider all emotions to be represented by a small number of dimensions that code for such constructs as valence (positive vs. negative), pleasure (pleasant vs. unpleasant), or emotional arousal (calm vs. excited). Although many investigators support the presence of a twodimensional system that can be applied to the recognition of emotion from multiple modalities (Russell \& Bullock, 1985) and to emotional experience (Russell, 1980), more complex models of this sort have also been described (Green \& Salovey, 1999; Russell \& Barrett, 1999; Watson, Wiese, Vaidya, \& Tellegen, 1999).

A convergence of evidence from studies of patients with brain damage (Robinson \& Manes, 2000), brainbased behavioral studies of patients with emotional disorders (Heller \& Nitschke, 1997), and EEG investigations of infants, healthy volunteers, adult clinical populations, and rhesus monkeys (Davidson, 1984; N. A. Fox \& Davidson, 1986; Kalin, Larson, Shelton, \& Davidson, 1998) suggests that positive and negative emotions are implemented by neural systems that are at least partially separable. Some models do not specify the precise neural representation of positive and negative emotions in any detail, only that different substrates are expected for both, whereas others assume differential involvement of the left hemisphere (LH) and the RH in coding different emotion dimensions (Davidson, 1984; Sackeim et al., 1982). Although the particular details differ from theory to theory, perhaps the most influential and wellspecified dimensional theory is the valence asymmetry model (Davidson, 1984). This model argues for differential contributions of left and right cortical regions in positive and negative emotions, respectively, with particular involvement of anterior or frontal brain regions. In this context, it is important to note that some researchers have drawn a distinction between emotion experience, on the one hand, and the perception or expression of emotion, on the other. Whereas the RH is believed to be critical in the perception and expression of emotion, as was noted above (Adolphs et al., 1996; Borod et al., 1998; Borod et al., 2001; Heller et al., 1998), the valence asymmetry model has typically been associated not only with the experience and expression of emotion (Davidson, Ekman, Saron, Senulis, \& Friesen, 1990), but also with individual differences in affective style (Davidson, 1998).
Yet other dimensional theorists have argued that emotions, and human behavior more generally, are psychological processes organized around approach and withdrawal action tendencies (Carver, Sutton, \& Scheier, 2000; Davidson, 1998; Lang, Bradley, \& Cuthbert, 1997; Schmidt \& Schulkin, 2000). Approach and withdrawal are considered to be basic response patterns fundamental to all complex adaptive behavior (Carver et al., 2000; Kinsbourne, 1978; Schneirla, 1959). In the context of human emotion, the approach system facilitates appetitive or goal-directed behavior and generates certain forms of positive affect that are approach related (Davidson \& Irwin, 1999). The withdrawal system, on the other hand, facilitates the withdrawal of an individual from sources of aversive stimulation and generates certain forms of negative affect that are related to withdrawal (Davidson \& Irwin, 1999).

As in the case of positive and negative emotions, a number of theorists have proposed distinct neuroanatomical underpinnings for approach and avoidance motivation (Cloninger, 1987, behavioral activation and behavioral inhibition systems; Davidson, 1998, approach and withdrawal systems; J. Gray, 1982, behavioral approach and behavioral inhibition systems; Lang, Bradley, \& Cuthbert, 1990, appetitive and aversive systems). The approachwithdrawal model represents a variation of the valence asymmetry model and applies only to a subset of such emotions, with differential involvement of left- and rightsided anterior neural activity in approach- and withdrawalrelated emotions, respectively. Although many investigators seem to equate positive and negative emotions with approach and withdrawal (Mendoza \& Ruys, 2001), others have offered critical distinctions, arguing that consideration of emotion in terms of its associated action tendency puts the emphasis on goal-directed emotion, rather than on postgoal attainment (Davidson, 1998; Davidson \& Sutton, 1995). In contrast to postgoal emotions, such as satiation and guilt, other emotions-for example, curiosity and fear-are specifically related to approach and withdrawal. It should be noted that Lang and colleagues include postgoal emotions in their appetitive category (Lang et al., 1997). Alternative theories of emotion lateralization have also been presented by other investigators, but a comprehensive overview of these models is beyond the scope of this article, and interested readers are referred to the following sources, among others (Buck, 1999; Gainotti, Caltagirone, \& Zoccolotti, 1993; Silberman \& Weingartner, 1986).

In contrast to the considerable amount of research attention dedicated to the study of emotional valence or action tendency, the neural correlates of emotional arousal have been neglected, and in fact, many studies confound these two dimensions of emotion. However, it has been suggested that arousal is reflected in overall levels of activation and that increased visual cortex activation may be a reliable index of the overall state of emotional arousal, especially in studies that employ visual 
emotional stimuli (Lang et al., 1998), although it should be noted that other researchers have suggested that emotional arousal is associated more specifically with activity of the amygdala (Gainotti et al., 1993; Williams et al., 2001).

\section{Multisystem Models of Emotion}

By direct contrast with the dimensional models of emotion described above, categorical accounts argue for the existence of a small set of discrete emotions mediated by central affect programs (Darwin, 1872; Ekman, 1992, 1999; Izard, 1971; Panksepp, 2000; Tomkins, 1982). Ekman's affect programs include the emotions of fear, disgust, anger, happiness, sadness, and surprise (Ekman \& Friesen, 1982; Ortony \& Turner, 1990). The term affect program refers to a (neural) mechanism that stores patterns for and triggers complex emotional responses that are often quick, complex, organized, and difficult to control. The basis for a limited set of affect program emotions arose out of research indicating that they are invariant across cultures and are represented by distinctive facial expressions (Ekman, 1992; Izard, 1971). Such a perspective is not necessarily incompatible with the dimensional frameworks described above. At least some dimensional theorists would argue that particular patterns of basic emotions tend to co-occur (Diener, 1999).

Ekman (1999) has argued that an important goal of neuroscientific study should be to identify unique patterns of CNS activity for each of the affect program emotions. In recent years, progress has been made on this front. Unlike broad dimensions of emotion, which have been linked to neural activity on a hemispheric basis, discrete emotions have been linked to activity in discrete neural regions or systems. As has been reviewed by Calder et al. (2001), recent neuropsychological case studies demonstrate impaired recognition of facial expressions of discrete emotions and emotional experience following specific brain lesions. This has been shown most convincingly for the emotions of fear (Adolphs, 1999; Adolphs, Tranel, Damasio, \& Damasio, 1994; Adolphs, Tranel, et al., 1999; Bechara et al., 1995; Calder et al., 1996; Schmolck \& Squire, 2001; Sprengelmeyer et al., 1999) and disgust (Calder, Keane, Manes, Antoun, \& Young, 2000; J. M. Gray, Young, Barker, Curtis, \& Gibson, 1997). For example, lesions to the amygdala and surrounding regions produce impairments in the recognition of facial expressions of fear, as well as fear responses, whereas lesions to circuitry that includes the gustatory insula and the basal ganglia lead to deficits in recognizing signals of disgust and in disgust responses. Although some preliminary work has begun to show that anger, too, may be linked to activity of a distinct neural system (Lawrence, Calder, McGowan, \& Grasby, 2002), regions considered critical for the recognition of happiness, sadness, or surprise have not yet been identified. The notion of central affect programs is also important for Panksepp's (2000) theory of emotion, but the details of his theory cannot be readily tested with the present data set.

As was noted above, evidence for the neural models presented has come from behavioral, lesion-based, and electrophysiological methodologies. Modern advances in FNI techniques afford new possibilities for the study of human emotions in intact populations, and naturally, there has been a tremendous increase in the number of such studies over the last decade. Considered in isolation, however, no one study can hope to characterize fully the neural basis for human emotion, since any conclusions that can be drawn may be specific to a certain experimental paradigm (e.g., fear conditioning), to a specific emotion condition (e.g., happiness), or to a particular subset of the population (e.g., women). An additional limitation of a typical neuroimaging study is that its conclusions are often severely compromised by limited statistical power. Thus, it is not yet clear to what extent the data emerging from recent positron emission tomography (PET) or functional magnetic resonance imaging (f MRI) studies might be consistent with these (or other) models, models that could continue to be useful in guiding our developing understanding of the neurobiology of human emotions.

One viable solution to these problems is to apply function-location meta-analytic techniques to large numbers of neuroimaging studies that address human emotions (P. T. Fox, Parsons, \& Lancaster, 1998). Function-location meta-analysis is typically used in the collective analysis of FNI data combined from multiple studies, in place of the standard effect-size meta-analysis, because it is the location, rather than the magnitude, of the effect that is of primary interest. An important benefit of functionlocation meta-analysis is that the exclusion of negative data has very little effect on the results (P. T. Fox et al., 1998). Function-location meta-analysis additionally provides the experimenter with increased statistical power and includes information on large numbers of participants, something that cannot be achieved in any single neuroimaging experiment. It allows researchers to recognize heterogeneity in research findings (P. T. Fox et al., 1998; Moller \& Jennions, 2001), to identify neural regions that are recruited across different emotion conditions (Cabeza \& Nyberg, 2002), and to view the entire "landscape" of emotion studies. Advocates of metaanalytic techniques have argued that new hypotheses regarding elementary mental operations and their associated neural circuitry can also be generated via meta-analysis and that these can, in turn, be tested and confirmed by subsequent, prospective experiments (Cabeza \& Nyberg, 2000; P. T. Fox et al., 1998).

Here, we present a meta-analysis of the FNI literature on emotion processing in healthy volunteers, with a particular emphasis on the relationship of the regional distribution of neural activity to existing neural distribution models of human emotion. Our meta-analysis was guided by a number of specific hypotheses. First, we expected to find evidence for $\mathrm{RH}$ dominance in emotion 
processing - an effect potentially restricted to neuroimaging studies of emotion perception and/or posterior regions of the brain. Second, we predicted differences in the three-dimensional (3-D) distributions of neural activity associated with (1) positively versus negatively valenced emotions, (2) approach versus withdrawal emotions, and (3) the affect program emotions of fear, anger, disgust, happiness, and sadness. We applied novel statistical techniques to our data set in order to test these predictions. Third, superimposed upon the right-lateralized network for emotion, we expected to find evidence for hemispheric differences in the neural representation of positively and negatively valenced emotions or, perhaps more strongly, approach and withdrawal action tendencies. And finally, we anticipated the presence of specific associations between certain affect program emotions (fear and disgust) and specific neural regions (the amygdala and the insula/basal ganglia, respectively) that have been identified in previous neuropsychological investigations, as has been described above.

\section{METHOD}

\section{Scope of Studies Included}

In this meta-analysis, we have included neuroimaging studies that focus on emotional processes or employ emotional tasks or paradigms. Depending on the particular framework, the term emotion has been used to refer to the perception and interpretation of emotion signals, subjective emotion experience, or the behavioral expression of emotions, each of which might have different neural substrates. Here, we combine studies from each of these perspectives, and the term emotional is used to describe any stimulus or paradigm not considered to be emotionally neutral in tone, but positive or negative in valence or related to approach or avoidance action tendencies. Studies focusing on motivational phenomena, such as reward and punishment, pain, or sexual motivation, have been excluded, except in instances in which independent emotion ratings indicated changes in valence or action tendency. All studies were conducted using $\mathrm{H}_{2}{ }^{15} \mathrm{O}$ PET or fMRI.

Studies considered for inclusion were initially identified by computerized and manual search of electronic databases (MEDLINE, PsychLit, and Web of Science ISI) and relevant journals, covering the period January 1994 to December 2001. To allow ease of comparison between studies, our data set was restricted to those studies that reported their findings in a standardized anatomical space according to the atlas of Talairach and Tournoux (1988) or the Montreal Neurological Institute/International Consortium for Brain Mapping (Brett, Johnsrude, \& Owen, 2002; Collins, Neelin, Peters, \& Evans, 1994). Potential studies were further considered with the following constraints in mind.

1. The studies chosen were limited to those assessing emotion in healthy volunteers; patient studies and pharmacological or dietary manipulations of emotional state were not included (e.g., tryptophan depletion or procaine-induced emotional states, respectively).

2. Because experimental and control tasks that involve very different processes are likely to show a broad range of differences in brain activity-only some of which are likely to be related to the particular factor the experiment is intended to investigate-we included only those studies that employed matched neutral control conditions. Studies comparing emotional experimental conditions with much simpler control conditions (e.g., resting state) were excluded.

3. Neuroimaging studies measuring activity in the whole brain and region-of-interest (ROI) studies were included in asymmetry analyses as long as standard coordinates were given, but ROI studies were excluded from the KS3 and regional analyses described below, primarily because the absence of activity in unsampled brain regions is not informative in restricted region studies. Thus, ROI studies have been identified in Table 1, and details concerning the specific brain regions targeted in individual studies have been noted.

4. Presentation of results has been limited to regional activation changes (as revealed by task comparison or image subtraction method, parametric designs, and brain-behavior correlations); data on changes in functional or effective connectivity have been excluded, as have studies reporting only an interaction between emotion and time, rather than a main emotion effect (e.g., Simpson et al., 2000; Tabert et al., 2001). The statistical approach(es) adopted for individual studies should be evident from the "Specific Contrasts" column of Table 1.

5. Only activation data were included in the relevant analyses; deactivation data were excluded.

6. In order to sidestep debate concerning what constitutes neural activity of "significant" magnitude, we have included all changes in signal that the authors of individual papers have labeled "significant." These changes were based on peak voxel maxima effects, regardless of cluster extent.

In total, we analyzed data from 106 neuroimaging studies of emotion processing (62 PET and $44 \mathrm{fMRI}$ ) in healthy volunteers, yielding 181 separate contrasts and 1,167 activation peaks. Table 1 details the studies included in this meta-analysis. For each experiment included, we have provided information about the following (from left to right): (1) neuroimaging method (e.g., PET or fMRI), (2) the number and sex of participants, (3) the experimental paradigm employed (e.g., emotion perception, induced mood, conditioned fear, emotional decisions/judgments, or memory for emotional materials), (4) the specif ic contrasts of interest and the targeted emotion, valence, or action tendency (e.g., happiness, anger, positive emotion, withdrawal emotion, etc.), and (5) the modality of stimulus material presentation (e.g., visual, auditory, olfactory, or gustatory).

\section{Data Analysis}

When combining data for a meta-analytic review, it is important to ensure that a common coordinate system is adopted across all studies. As was noted above, we have restricted our data set to those studies presenting 3-D activation maxima in millimeters from the anterior commissure for the $x$-, $y$-, and $z$-planes $(x$, right $[+] / \operatorname{left}[-]$; $y$, anterior $[+] /$ posterior $[-] ; z$, superior $[+] /$ inferior $[-])$. However, the precise standardized coordinate system can differ according to the specific analysis software used in individual studies. For example, whereas SPM95 uses the standardized coordinate system of Talairach and Tournoux (1988), SPM96 and SPM99 use a slightly larger standardized brain from the Montreal Neurological Institute (MNI; Brett et al., 2002; Collins et al., 1994). Thus, we have converted all peak activation coordinates into MNI space, using the transformation algorithm TAL2MNI developed by Matthew Brett (http://www.mrc-cbu.cam.ac.uk/Imaging/) and used in previous meta-analytic research (see Brett, Christoff, Cusack, \& Lancaster, 2001; Calder et al., 2001; Duncan \& Owen, 2000). Three types of analysis were conducted, depending on the particular hypothesis under consideration.

1. Testing for differences in the 3-D activation patterns across different emotion conditions. The standard Kolmogorov-Smirnov statistic (KS1) is the basis of a well-known nonparametric statistical test for assessing differences of distribution between two sets of data. This test compares the empirical distribution functions of the two samples of numerical data on the $x$-axis. At each test point $T$ on the $x$-axis, there is an empirical difference or discrepancy in the proportions of the two samples that lie in one or the other of the two sections of the $x$-axis to either side of $T$. The KS1 statistic is the maximum of this discrepancy across all possible $T$ s on the $x$-axis. A KS1 value of, say, .28 means that there is a section of the $x$-axis on which there is a difference of $28 \%$ between the fractions of the two samples contained in that section and that this is the biggest 
such difference that could be found across all sections of the $x$-axis. Under the null hypothesis that the two samples come from the same unknown distribution, the KS1 statistic can be used in a significance test in which the null hypothesis is rejected for large values of KS1. The significance of KS1 can be assessed against a known asymptotic distribution or by means of a bootstrap (approximate permutation) test (Praestgaard, 1995). In the latter case, the two data samples are combined, a large number (here 1,000) of new random samples of the same sizes as in the original data are constructed, and their KS1 statistics are calculated. An estimated $p$ value for the observed KS1 statistic is calculated from the fraction of the simulated KS1 values that are at least as large as the observed one. The $p$ value is used to make a Fisher-type significance test. Aside from small errors in estimation of the $p$ value, if the bootstrap KS1 test is used in a Neyman-Pearson hypothesis-testing framework with prespecified size $\alpha$, its false positive rate will be exactly $\alpha$. Because of the nonspecific nature of the alternative to the null hypothesis, the fact that the KS1 test is significant does not translate into a specific localized difference in the two underlying distributions.

The 3-D Kolmogorov-Smirnov statistic (KS3), which has been used in previous meta-analytic research (Duncan \& Owen, 2000), is a generalization of the above KS 1 construction to testing for equality of the distributions of two samples of $x y z$-data. The discrepancy of the distribution at a point $T$ in $x y z$-space is the largest of the differences in the fractions of the two samples that lie in each of the eight subdivisions (octants) created by the three orthogonal planes through $T$ parallel to the $x y$-, $x z-$, and $y z$-planes. The KS3 statistic is the maximum of this discrepancy for all possible $T \mathrm{~s}$ in $x y z$-space. Unlike KS1, KS3 does not in general have a null-hypothesis distribution that is independent of the common distribution (Fasano \& Franceschini, 1987), and the bootstrap version of the KS3 test is indicated. A KS3 value of, say, .28 means that there is an octant of the $x y z$-space in which there is a difference of $28 \%$ between the fractions of the two samples contained in that section and that this is the biggest such difference that could be found across all octants. In the analyses that are reported here, KS3 is calculated using algorithms coded in the MATLAB language that incorporate binary search tree methods that reduce the overall computational requirements. Although the bootstrap KS3 has the same lack of bias in false positive rate as KS1, it also lacks specificity as to how or where the distributions differ. Specific aspects of comparative spatial distributions can be tested by more familiar nonparametric tests, such as the binomial test and the chi-squared test.

For each of the following comparisons, we used the KS3 to compare the 3-D distribution of activation foci for each emotion category, in turn, with each of the others: (1) emotion valence (positive vs. negative emotions), (2) action tendency (approach vs. withdrawal emotions), and (3) affect program emotions (fear vs. disgust vs. anger vs. happiness vs. sadness). The positive emotions category included emotional stimuli or responses that could be described as positive and were related to such emotions as love, happiness, pleasantness, and humor. The negative emotions category included emotional stimuli and responses related to such emotions as sadness, anger, fear, anxiety, and unpleasantness. The contrasts included for approach and withdrawal emotions mapped quite closely onto those included for positive and negative emotions, respectively, but there were two notable exceptions. First, anger was included in the approach emotions category, since it is thought by some investigators to involve predominantly approach motivational tendencies (Depue \& Iacono, 1989). Second, studies targeting sadness were not included in our withdrawal emotions category, since it has been suggested that sadness is characterized by a reduction in approach-rela ted, rather than heightened avoidance, behavior (Depue \& Iacono, 1989; Lane, Reiman, Ahern, Schwartz, \& Davidson, 1997). The specif ic contrasts and studies included for each of these categories are detailed in Table 1.

2. Testing for hemispheric differences. In order to assess the RH hypothesis of emotion described in the introduction, we computed the total number of activation peaks in anterior $(y>0)$ and posterior $(y<0)$ regions of the $\mathrm{LH}$ and the $\mathrm{RH}$ for all of the studies included in this meta-analysis. This strategy was also applied to those emotion conditions for which the spatial distributions were found to differ significantly on the basis of the KS3 test described above or for which neuroscientific theory postulates hemispheric differences. The binomial or sign test was then used to test for straightforward left-right differences, and also where relevant, the chi-squared test was used to assess whether any observed asymmetries were more marked for anterior than for posterior brain regions. The results reported for binomial tests are one-sided, unless specif ied otherwise.

3. Regional specialization for discrete emotions. We tested for a relationship between activation of specific neural regions and each of the affect program emotions-fear, disgust, anger, happiness, and sadness-by determining the most consistently activated region for each emotion. The most consistently activated region for each emotion was defined as the brain region that was reported as significantly active in the largest proportion of studies for each affect program emotion. By way of illustration, if the amygdala, for example, was active in, say, $75 \%$ of fear studies (irrespective of size of cluster or number of peaks in each individual study), the cerebellum in $40 \%$ of fear studies, the anterior cingulate cortex (ACC) in $63 \%$ of fear studies, and so on, the amygdala would be considered the most consistently activated region for the emotion of fear. Restricted region studies were not included in this analysis.

Anatomical labels for each 3-D activation point were determined in the following way. First, all points were transformed into Talairach coordinates (using the MNI2TAL algorithm of Matthew Brett where necessary). Labels were assigned to activation points by direct comparison with the atlas of Talairach and Tournoux (1988), together with the aid of the on-line Talairach Daemon Database (Lancaster et al., 2000). In addition, the ACC was divided into three subdivisions, following recently established criteria (Paus, Koski, Caramanos, \& Westbury, 1998; Paus et al., 1996): (1) a caudal ACC division, (2) a rostral supracallosal ACC region (this region included parts of the dorsomedial prefrontal cortex, but excluded the supplementary motor area and frontal polar regions [Öngür, Ferry, \& Price, 2003; Paus et al., 1998]), and (3) a subcallosal ACC region (this region also included caudal regions of the medial orbitofrontal cortex [OFC; Öngür et al., 2003] ). In addition, we followed Small (Small et al., 1999) in defining a combined insula-frontalopercular region, which was distinct from a lateral orbitofrontal region (the latter region including Talairach BA 47).

It should be emphasized before proceeding that the results of the KS3 and our regional analysis represent different ways of considering the same data set. Thus, if the KS3 indicates that Emotion A and Emotion B differ in terms of their 3-D patterns of neural activity and the regional analysis further shows that Brain Region $\mathrm{X}$ is most consistently active for Emotion A, but not for Emotion B, it does not necessarily follow that this single change or many are producing the significant KS3 result.

For each of the above analyses, the data were collapsed across emotion perception (visual, auditory, etc.) and production/experience. By production, we refer not only to voluntary production, but also to reflexive or passive emotional responses. Where relevant to the specific hypothesis under consideration, additional analyses were performed on a subset of studies that employed facial expressions of emotion as stimuli, since analysis of this subset of emotion studies provides a potentially "cleaner" test of the hypotheses outlined in the introduction.

\section{RESULTS}

\section{Right-Hemisphere Hypothesis}

Table 2 details the total number of activation peaks, as a function of left/right hemisphere and anterior/posterior regions of the brain, for each of the emotion categories 


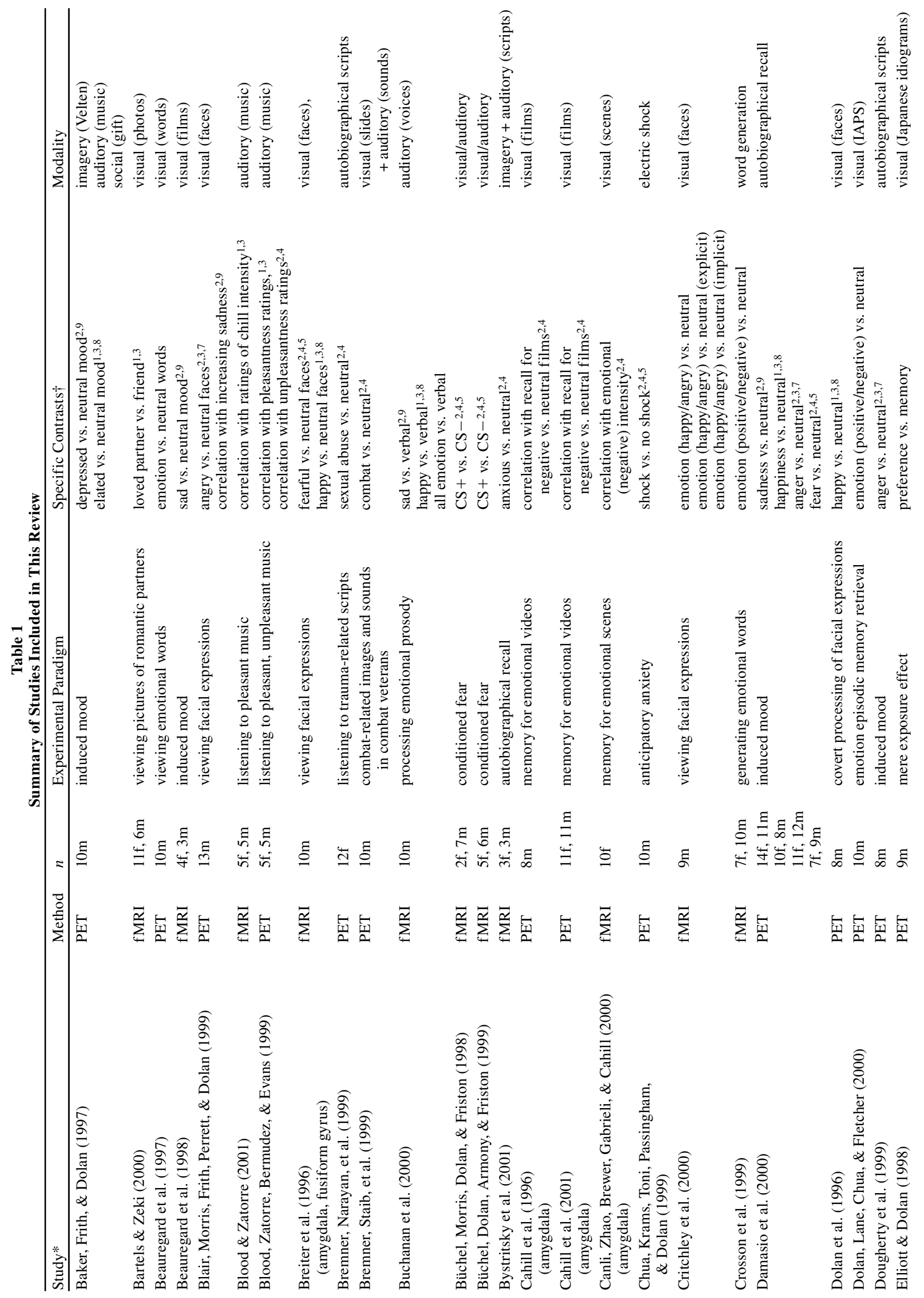




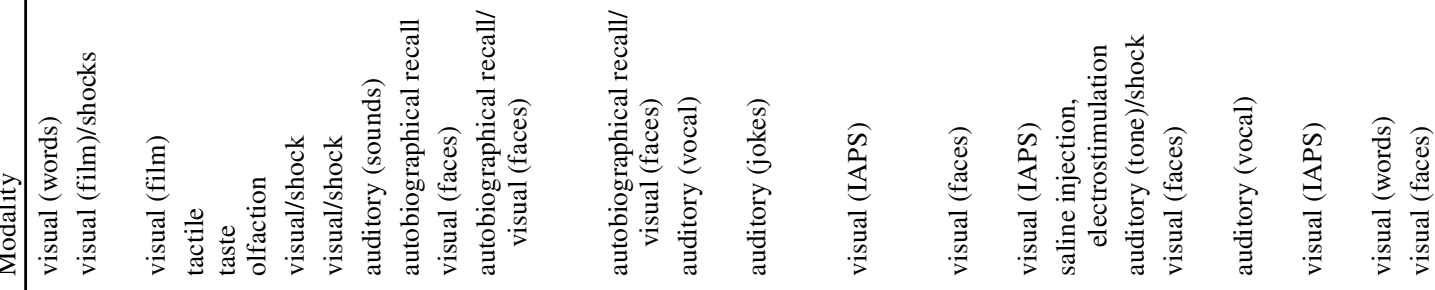

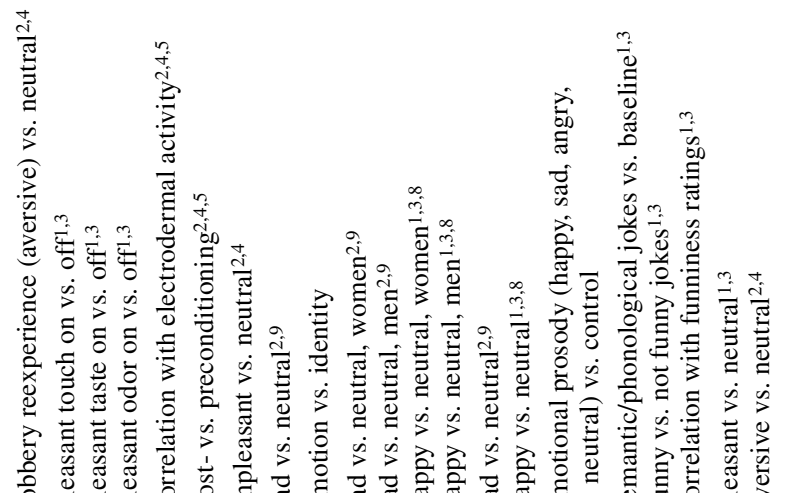

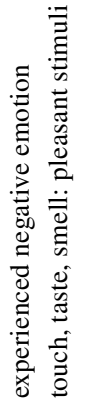

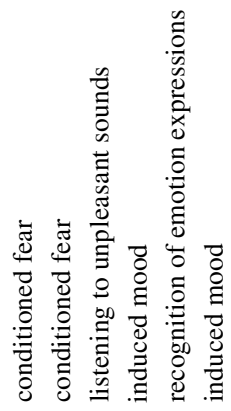

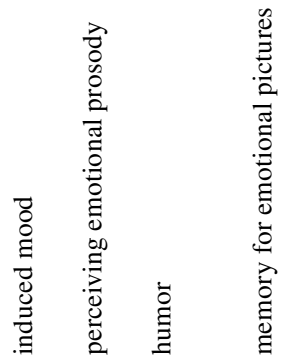

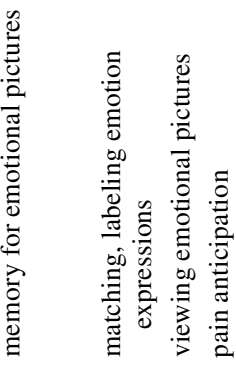
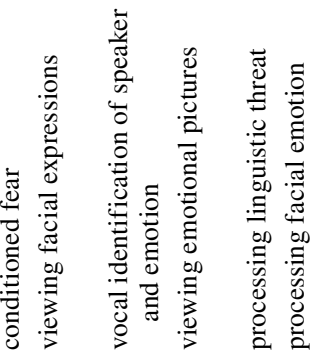

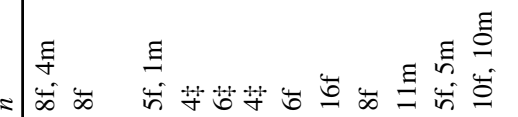

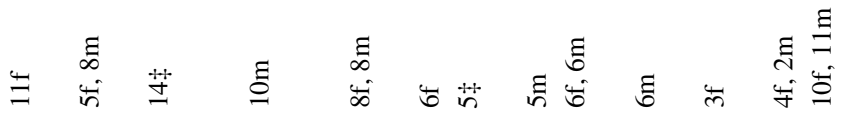

형

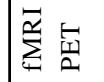

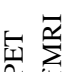

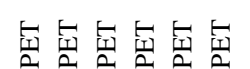

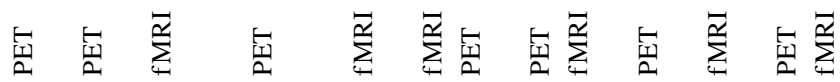

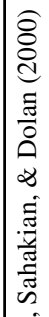

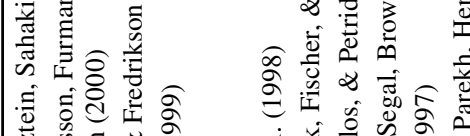

जै:

产

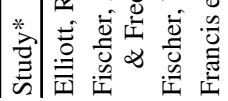

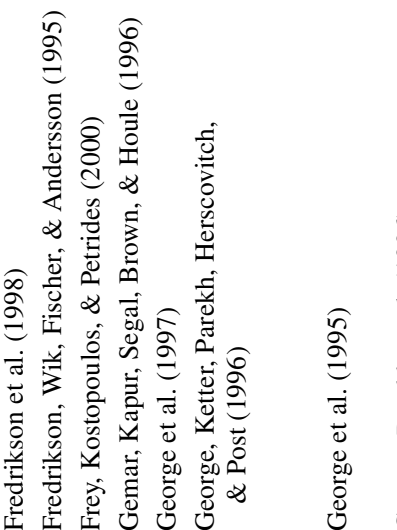

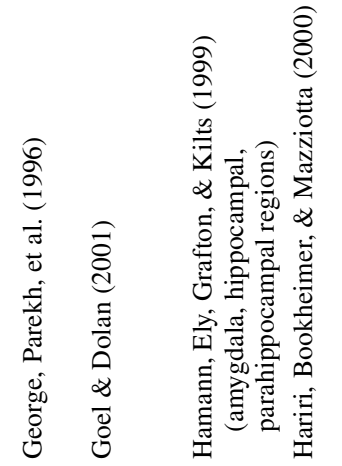

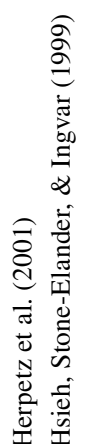

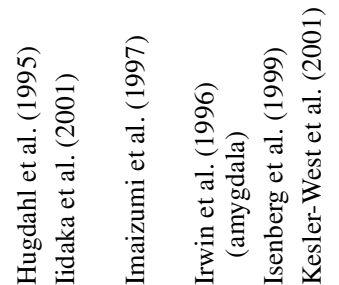




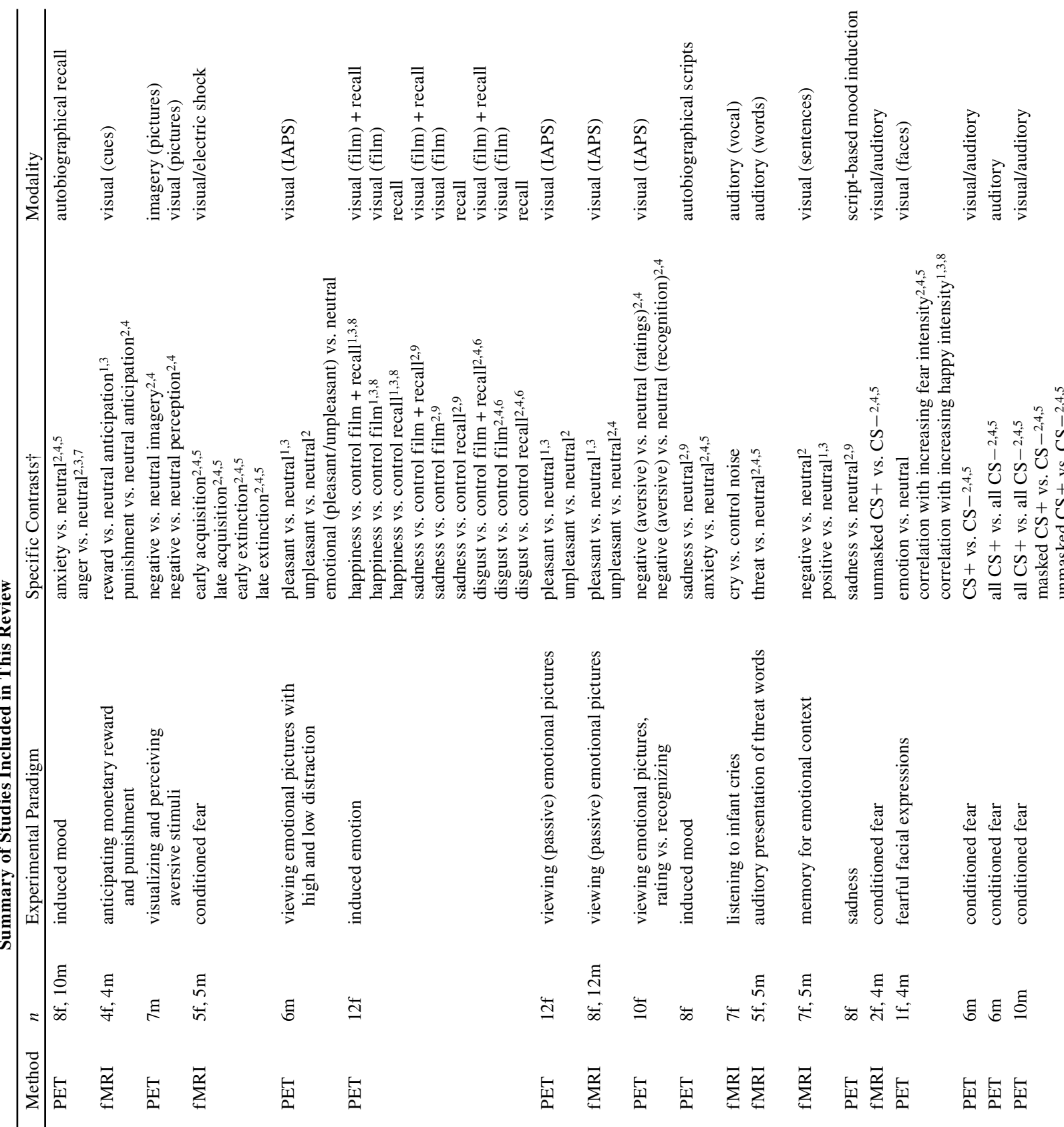




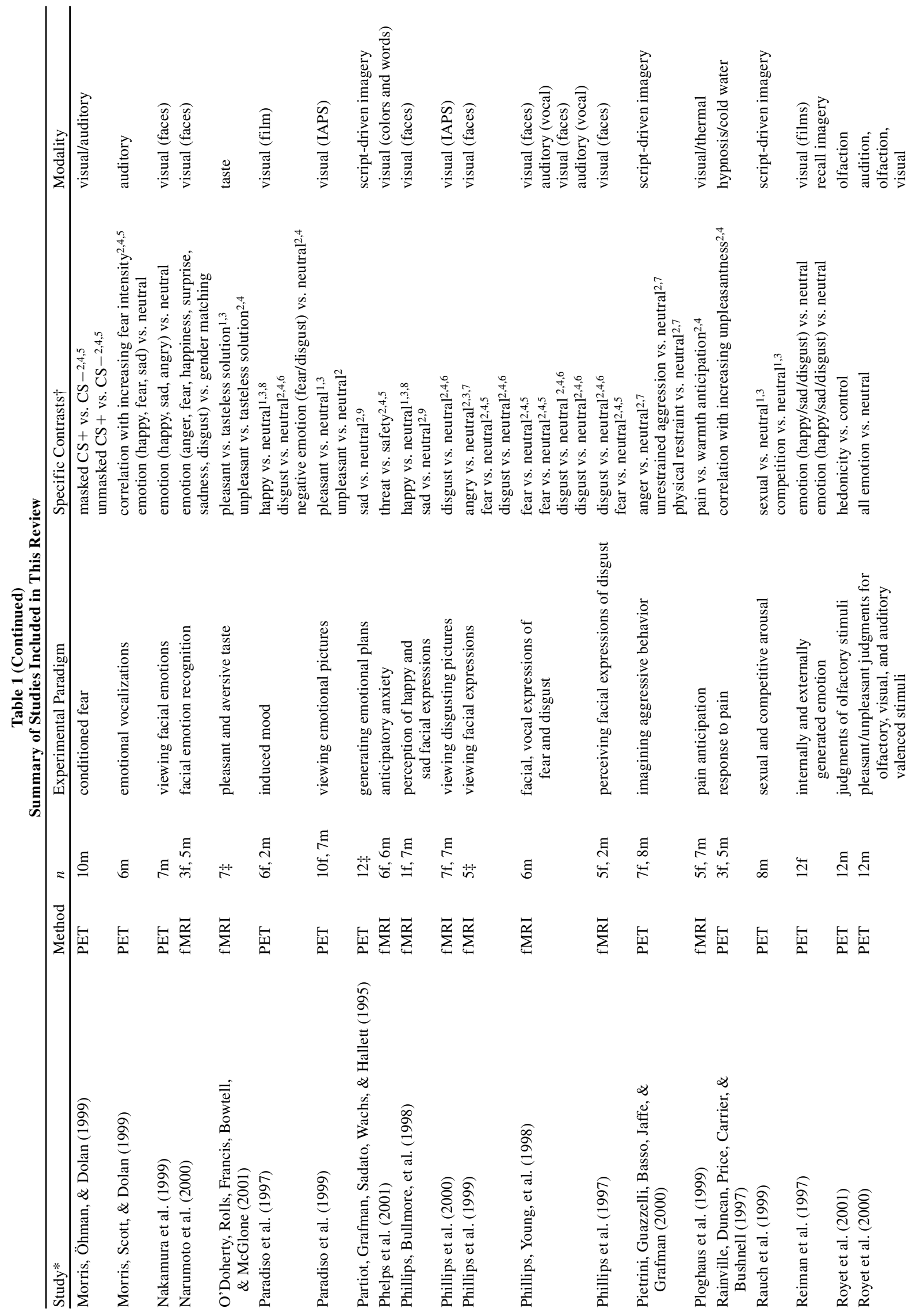




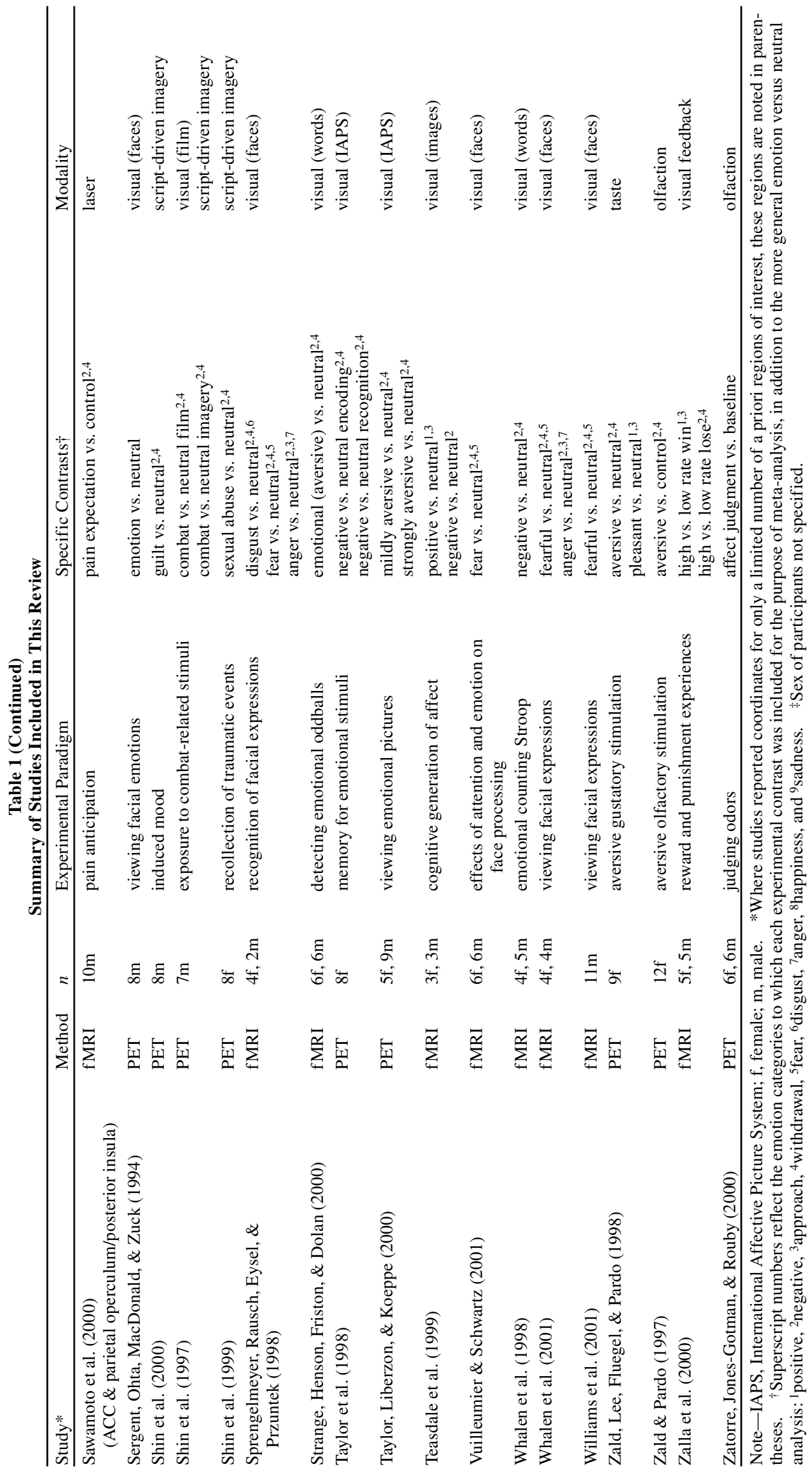


Table 2

Frequency of Reported Activation Maxima ( $x$-, $y$-, and $z$-Coordinates)

for Each of the Emotion Conditions, as a Function of

Left/Right Hemisphere and Anterior/Posterior Regions of the Brain

\begin{tabular}{|c|c|c|c|c|c|}
\hline \multirow{2}{*}{$\begin{array}{l}\text { Emotion } \\
\text { Condition } \\
\end{array}$} & \multirow{2}{*}{$\begin{array}{c}\text { Total } \\
\text { Studies } \\
\end{array}$} & \multirow{2}{*}{$\begin{array}{c}\text { Total Maxima } \\
\text { Reported }\end{array}$} & \multirow[b]{2}{*}{ Region } & \multicolumn{2}{|c|}{$\underline{\text { Summary Counts }}$} \\
\hline & & & & Left & Right \\
\hline \multirow[t]{3}{*}{ All emotion } & 106 & 1,163 & whole brain & 589 & 547 \\
\hline & & & anterior & 227 & 226 \\
\hline & & & posterior & 355 & 312 \\
\hline \multirow[t]{3}{*}{ Positive } & 30 & 237 & whole brain & 126 & 106 \\
\hline & & & anterior & 55 & 54 \\
\hline & & & posterior & 69 & 48 \\
\hline \multirow[t]{3}{*}{ Negative } & 81 & 788 & whole brain & 391 & 378 \\
\hline & & & anterior & 146 & 140 \\
\hline & & & posterior & 241 & 232 \\
\hline \multirow[t]{3}{*}{ Approach } & 36 & 307 & whole brain & 165 & 134 \\
\hline & & & anterior & 74 & 64 \\
\hline & & & posterior & 89 & 66 \\
\hline \multirow[t]{3}{*}{ Withdrawal } & 62 & 509 & whole brain & 251 & 256 \\
\hline & & & anterior & 82 & 88 \\
\hline & & & posterior & 167 & 164 \\
\hline \multirow[t]{3}{*}{ Fear } & 30 & 221 & whole brain & 112 & 129 \\
\hline & & & anterior & 30 & 41 \\
\hline & & & posterior & 81 & 88 \\
\hline \multirow[t]{3}{*}{ Disgust } & 7 & 97 & whole brain & 51 & 46 \\
\hline & & & anterior & 15 & 12 \\
\hline & & & posterior & 35 & 33 \\
\hline \multirow[t]{3}{*}{ Anger } & 9 & 74 & whole brain & 41 & 30 \\
\hline & & & anterior & 20 & 10 \\
\hline & & & posterior & 21 & 2 \\
\hline \multirow[t]{3}{*}{ Happiness } & 12 & 81 & whole brain & 46 & 32 \\
\hline & & & anterior & 21 & 11 \\
\hline & & & posterior & 24 & 20 \\
\hline \multirow[t]{3}{*}{ Sadness } & 14 & 164 & whole brain & 78 & 73 \\
\hline & & & anterior & 39 & 35 \\
\hline & & & posterior & 77 & 71 \\
\hline
\end{tabular}

across all studies. Analysis of maxima for all studies in which emotional processes were investigated, collapsed across perception and production/experience of emotion, failed to reveal a greater frequency of right- relative to left-sided maxima. Instead, more left- than right-sided activations were observed $(\mathrm{L}=589, \mathrm{R}=547)$, although a binomial test revealed that this difference was not significant $(p=.11)$ and did not vary as a function of anterior versus posterior brain regions $\left[x^{2}(1)=1.05, p=.33\right]$. Figure 1A shows the widespread pattern of neural activity associated with all the emotional processes and tasks represented by the studies included in this meta-analysis.

The total numbers of left- and right-sided activation peaks for the subset of studies employing facial expressions of emotion are presented in Table 3 . Analysis of this restricted subset of studies did not demonstrate a critical role for the RH in the perception of emotion either, with approximately equivalent numbers of activation maxima in the $\mathrm{LH}$ and the RH for both anterior $(\mathrm{L}=$ $33, \mathrm{R}=35)$ and posterior $(\mathrm{L}=75, \mathrm{R}=81)$ brain regions $\left[x^{2}(1)=0.004, p=.95\right]$.

\section{Valence: Positive Versus Negative Emotions}

The spatial distributions associated with positive and negative emotions (Figure 1B) were not found to differ significantly on the basis of the KS3 analysis $(\mathrm{KS} 3=.123$, $p=.14)$.

With respect to hemispheric effects (see Table 2), greater left- than right-sided activity was not found in the analysis of positive emotions ( $\mathrm{L}=126, \mathrm{R}=106 ; p=.10$, one-sided). The distribution of $x$-coordinates for negative emotions was relatively symmetrical as well $(\mathrm{L}=$ $391, \mathrm{R}=378 ; p>.3$ ] for both anterior and posterior regions $\left[x^{2}(1)=0.001, p=.52\right.$, one-sided $]$.

Application of the binomial test to the subset of studies that employed facial expressions did not reveal significant differences in hemispheric asymmetry for either positive or negative emotions (see Table $3 ; p>.15$, onesided).

\section{Action Tendency: Approach Versus Withdrawal Emotions}

Application of the KS3 test to the entire data set revealed a significant difference in the spatial distributions associated with approach and withdrawal emotions $(\mathrm{KS} 3=.174, p<.001$; Figure 1C).

The numbers of left- and right-sided maxima for studies targeting examples of approach and withdrawal emotions are presented in Table 2. A subsequent and more refined hemispheric analysis of these data demonstrated 


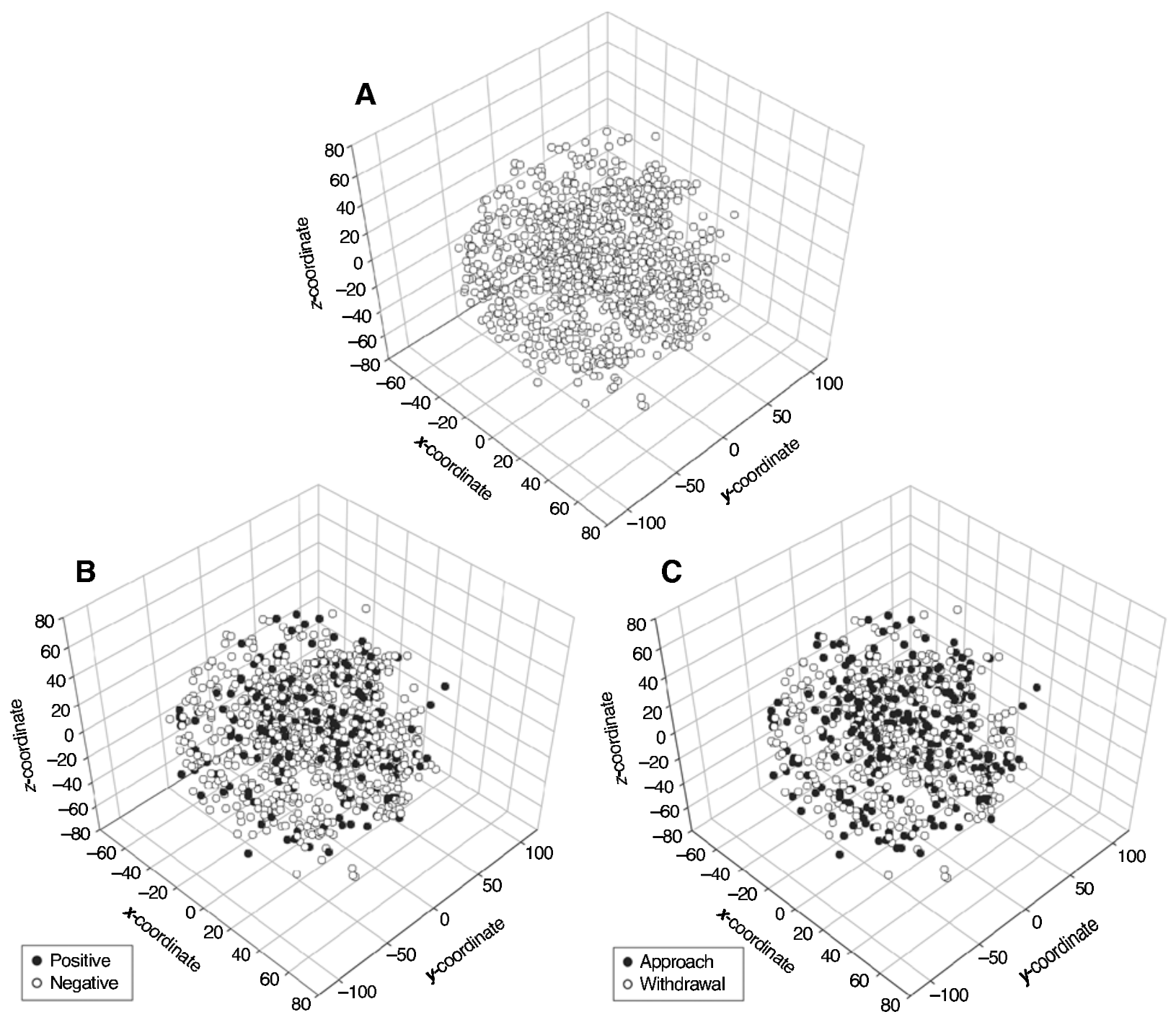

Figure 1. Three-dimensional scatterplots showing distributions of activation foci for contrasts associated with (A) all emotions, (B) positive/negative valence emotions, and (C) approach/withdrawal emotions.

significantly greater left- than right-sided activation for approach emotions $(\mathrm{L}=165, \mathrm{R}=134 ; p<.05)$, although this pattern was not restricted to anterior brain regions $\left[x^{2}(1)=0.43, p=.3\right]$. The numbers of left- and rightsided peak maxima were not found to differ in the analysis of withdrawal-related emotions $(\mathrm{L}=251, \mathrm{R}=256 ; p>.3)$, nor did they vary as a function of anterior-posterior regions of the brain $\left[x^{2}(1)=0.22, p=.35\right.$, one-sided $]$.

As can be seen from Table 3, when only the studies that employed facial expressions of emotion were considered, there appeared to be a greater number of rightrelative to left-sided maxima for withdrawal emotions in posterior brain regions, though this was not significant $(p=.14)$. Although slightly more left- relative to rightsided maxima were observed for approach emotions, this association did not achieve significance either $(p=.10$, one-sided; see Table 3).

\section{Affect Program Emotions}

The results of the KS3 analyses comparing each affect program emotion with each of the others, in turn, are presented in Table 4. The 3-D distributions for fear versus disgust were found to differ significantly, as were the spatial distributions for fear versus anger and fear versus sadness (but not fear vs. happiness). Furthermore, the spatial distribution for disgust was found to differ not only from fear, but also from anger, happiness, and sadness. The 3-D activation pattern for anger differed significantly from that for sadness and approached significance for that for happiness. By contrast, no significant difference was found between the spatial distributions for happiness and sadness.

Although the affect program emotions have not typically been considered in the context of asymmetric models of emotion, analysis of certain affect program emo- 
Table 3

Frequency of Reported Activation Maxima ( $x$-, $y$-, and $z$-Coordinates) for Each of the Emotion Conditions From Only Those Studies That Used Facial Expressions of Emotion as Stimuli

\begin{tabular}{|c|c|c|c|c|c|}
\hline \multirow{2}{*}{$\begin{array}{c}\text { Emotion } \\
\text { Condition }\end{array}$} & \multirow{2}{*}{$\begin{array}{c}\text { Total } \\
\text { Studies }\end{array}$} & \multirow{2}{*}{$\begin{array}{c}\text { Total Maxima } \\
\text { Reported }\end{array}$} & \multirow[b]{2}{*}{ Region } & \multicolumn{2}{|c|}{ Summary Counts } \\
\hline & & & & Left & Right \\
\hline \multirow{3}{*}{ All emotion } & 20 & 230 & whole brain & 111 & 118 \\
\hline & & & anterior & 33 & 35 \\
\hline & & & posterior & 75 & 81 \\
\hline \multirow[t]{3}{*}{ Positive } & 6 & 22 & whole brain & 10 & 11 \\
\hline & & & anterior & 3 & 1 \\
\hline & & & posterior & 7 & 10 \\
\hline \multirow[t]{3}{*}{ Negative } & 12 & 163 & whole brain & 76 & 87 \\
\hline & & & anterior & 27 & 27 \\
\hline & & & posterior & 47 & 58 \\
\hline \multirow[t]{3}{*}{ Approach } & 10 & 70 & whole brain & 39 & 30 \\
\hline & & & anterior & 10 & 7 \\
\hline & & & posterior & 28 & 23 \\
\hline \multirow[t]{3}{*}{ Withdrawal } & 8 & 131 & whole brain & 60 & 71 \\
\hline & & & anterior & 19 & 19 \\
\hline & & & posterior & 39 & 50 \\
\hline \multirow[t]{3}{*}{ Fear } & 10 & 90 & whole brain & 43 & 46 \\
\hline & & & anterior & 14 & 11 \\
\hline & & & posterior & 29 & 35 \\
\hline \multirow[t]{3}{*}{ Disgust } & 4 & 41 & whole brain & 16 & 25 \\
\hline & & & anterior & 5 & 8 \\
\hline & & & posterior & 10 & 15 \\
\hline \multirow{3}{*}{ Anger } & 5 & 24 & whole brain & 12 & 12 \\
\hline & & & anterior & 6 & 5 \\
\hline & & & posterior & 6 & 7 \\
\hline \multirow[t]{3}{*}{ Happiness } & 6 & 22 & whole brain & 10 & 11 \\
\hline & & & anterior & 3 & 1 \\
\hline & & & posterior & 7 & 10 \\
\hline \multirow[t]{3}{*}{ Sadness } & 3 & 3 & whole brain & 2 & 1 \\
\hline & & & anterior & 0 & 1 \\
\hline & & & posterior & 2 & 0 \\
\hline
\end{tabular}

Note-Coordinates with $x=0$ or $y=0$ were excluded in the asymmetry counts.

tions that have clear associations with certain action tendencies (e.g., fear-withdrawal, disgust-withdrawal, anger-approach; see Frijda, 1986) was thought to provide a "cleaner" test of whether brain function is lateralized for approach and withdrawal. On the basis of prior research, a binomial test was employed to analyze frontal maxima only. This revealed greater left- than right-sided activity for both happiness $(p=.05)$ and anger $(p=.05$; see Table 2). In contrast, the other affect program emotions were associated with relatively symmetrical patterns of neural activity ( $p$ values $>.25$ ). In Figures $2 \mathrm{~A}-2 \mathrm{E}$, we plot the distribution of activation foci for each affect program emotion.
As was described above, we also tested for the presence of regional clustering associated with each of the discrete emotions. We determined the most consistently activated brain region (or regions, in cases in which more than one region was activated in the same proportion of studies) for each emotion and then computed the percentage of studies for each of the other emotions in which that same region was activated. Figure $3 \mathrm{~A}$ illustrates the most consistently activated regions for each of the discrete emotions: (1) fear-amygdala, (2) disgust-insula/ operculum and globus pallidus, (3) anger-lateral OFC, (4) happiness-rostral supracallosal ACC/dorsomedial PFC, and (5) sadness-rostral supracallosal ACC/dorso-

Table 4

Results of Three-Dimensional Kolmogorov-Smirnov Statistic Analyses (KS3) for Comparison of Each Affect Program Emotion With Each of the Others in Turn

\begin{tabular}{|c|c|c|c|c|c|c|c|c|c|c|}
\hline & \multicolumn{2}{|c|}{ Fear } & \multicolumn{2}{|c|}{ Disgust } & \multicolumn{2}{|c|}{ Anger } & \multicolumn{2}{|c|}{ Happiness } & \multicolumn{2}{|c|}{ Sadness } \\
\hline & KS3 & $p$ & KS3 & $p$ & KS3 & $p$ & KS3 & $p$ & KS3 & $p$ \\
\hline \multicolumn{11}{|l|}{ Fear } \\
\hline Disgust & .24 & .008 & & & & & & & & \\
\hline Anger & .31 & .002 & .30 & .013 & & & & & & \\
\hline Happiness & .19 & .18 & .24 & .05 & .24 & .093 & & & & \\
\hline Sadness & .23 & .002 & .27 & .004 & .28 & .003 & .13 & .85 & & \\
\hline
\end{tabular}




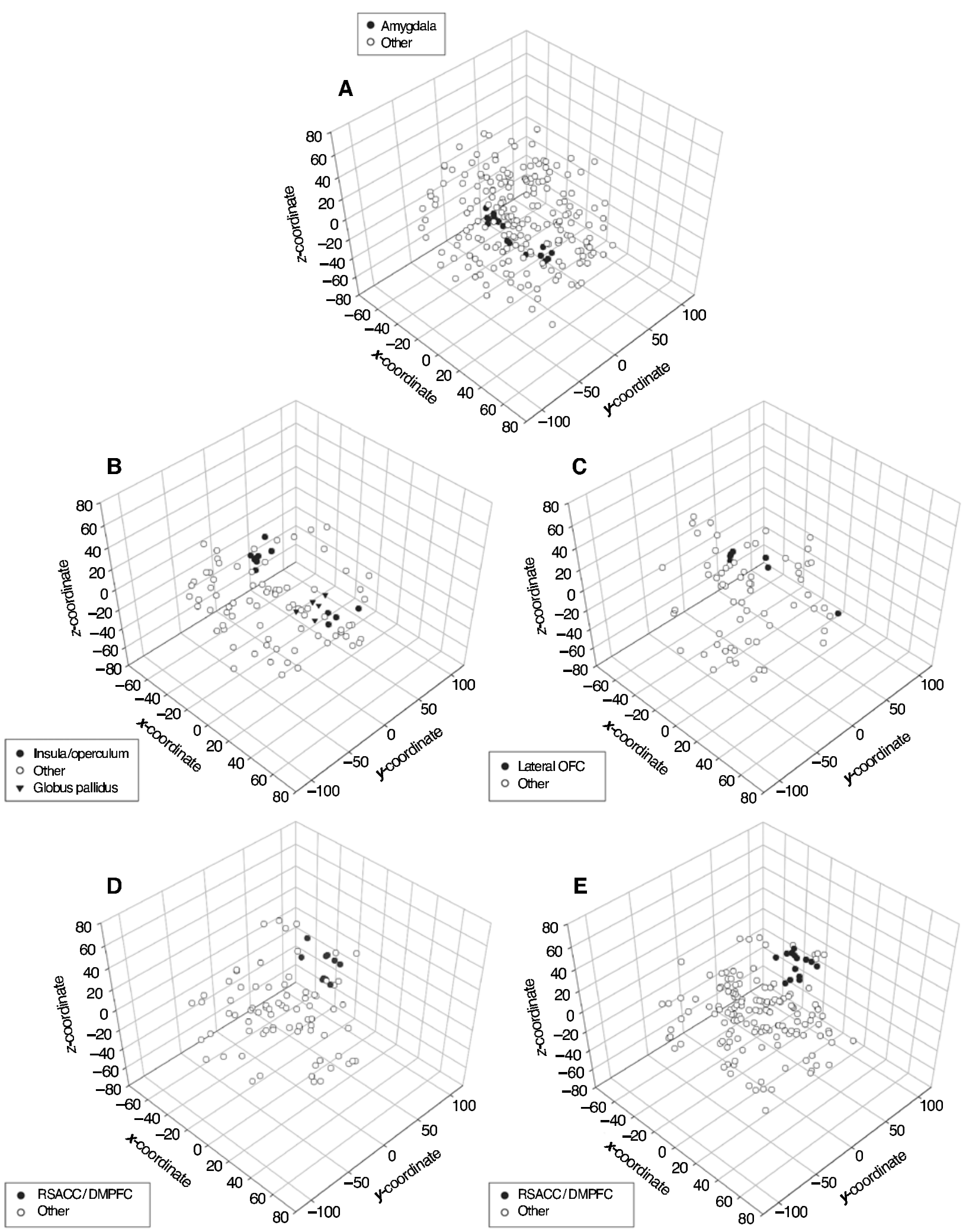

Figure 2. Three-dimensional scatterplots showing distributions of activation foci for contrasts associated with (A) fear, (B) disgust, (C) anger, (D) happiness, and (E) sadness. Filled symbols represent activations in regions most frequently associated with each particular emotion across studies. OFC, orbitofrontal cortex; RSACC, rostral supracallosal anterior cingulate cortex; DMPFC, dorsomedial prefrontal cortex. 


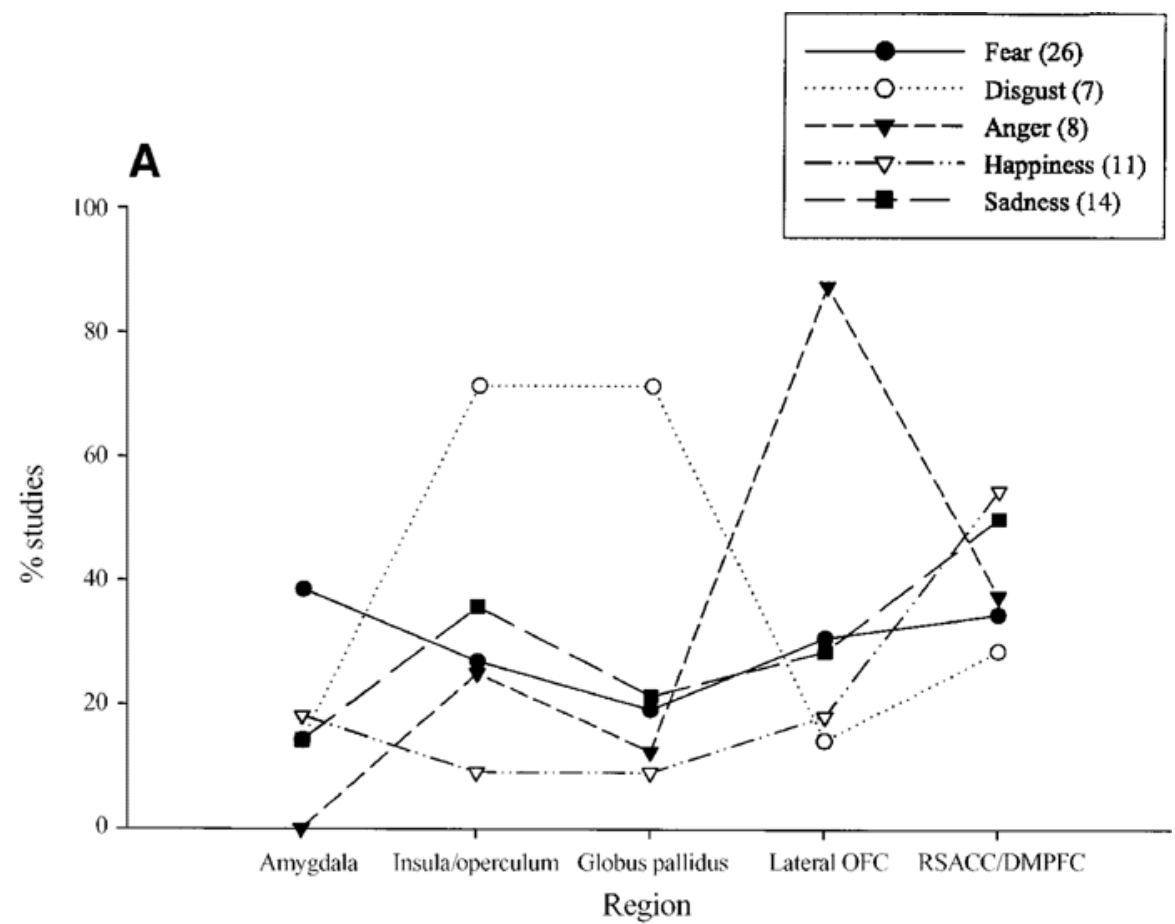

B
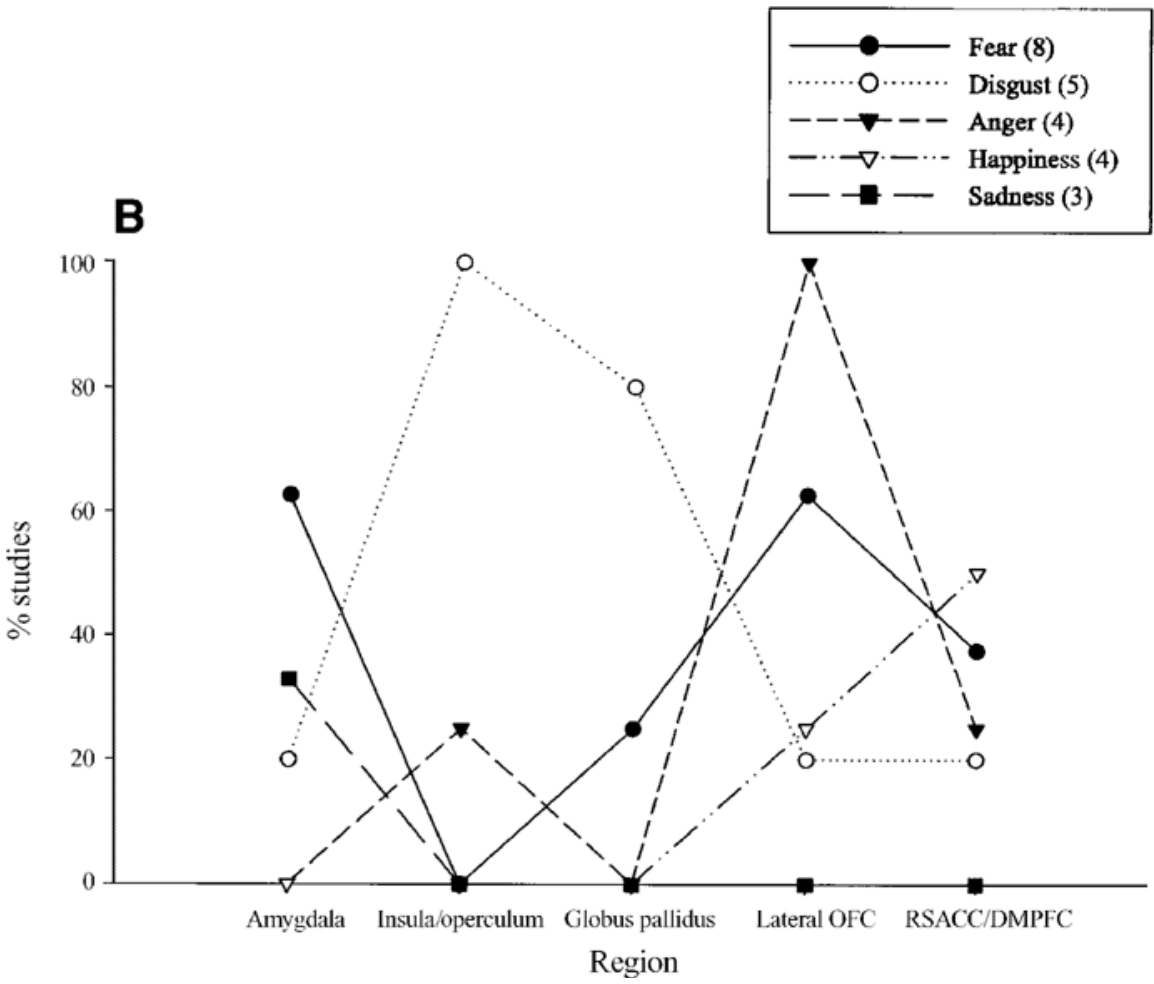

Figure 3. The proportion of studies targeting each of the affect program emotions associated with activation of the regions associated most consistently with each of those emotions: (1) the amygdala, (2) the insula/operculum, (3) the globus pallidus, (4) the lateral orbitofrontal cortex (OFC), and (5) the rostral supracallosal anterior cingulate cortex (RSACC)/dorsomedial prefrontal cortex (DMPFC). This is shown in panel A for all studies targeting the affect programs and in panel $B$ for the more focused subset of studies that used facial expressions of emotion as stimuli. 
medial PFC. In Table 5, the mean (and standard deviation) MNI $x y z$-coordinates are provided for each of the above discrete emotion-region pairings.

A similar pattern of findings was demonstrated in the more focused analysis of studies employing facial expressions of emotion. It can be seen from Figure $3 \mathrm{~B}$ that the associations reported above between (1) fear and the amygdala, (2) disgust and the insula/operculum, (3) disgust and the globus pallidus, and (4) anger and the lateral OFC emerged in this smaller subset of the data. Specifically, the amygdala was active in five out of eight fear studies, but in fewer than one study for each of the other affect program emotions. Both the insula/operculum and the globus pallidus were reported as significant in four and five of the seven studies targeting disgust, respectively, whereas activations of other regions for this emotion were far more variable. Similarly, the lateral OFC was active in all four of the studies targeting anger, although the lateral OFC was also active in a significant proportion of fear studies $(62.5 \%)$. Although the ACC figured prominently in studies targeting happiness (two out of four), the small number of studies that included sad facial expressions (three) and associated maxima makes it difficult to draw any reasonable conclusions.

While the general pattern of findings in this restricted analysis broadly reflects that seen in the larger analysis of all the affect program emotions described above, it could be argued that the face data are slightly less clear, due to the inclusion of smaller numbers of studies in this analysis.

\section{Spatial Smoothing}

Because the extent of spatial smoothing varies from one study to the next and because this can contribute to the number of significant activation foci, we felt it important to ensure that levels of smoothing did not vary dramatically across the different emotion conditions. We computed the mean size of spatial smoothing filter (FWHM) for each of our emotion conditions for those studies that provided the necessary information. The results of this analysis confirmed that the mean smoothing levels for positive and negative emotions did not differ significantly [positive $=12.1 \mathrm{~mm}$, negative $=12.6 \mathrm{~mm}$; $t(75)=-0.36, p=.7]$, nor did the means for approach and withdrawal emotions [approach $=12.8 \mathrm{~mm}$, withdrawal $=12.2 \mathrm{~mm} ; t(60)=0.43, p=.7]$. Mean smoothing levels were not found to vary significantly across the affect program emotions either $[F(4,39)=1.7, p=.19]$.

\section{DISCUSSION}

The main aim of the present study was to consider collectively the results of a large number of neuroimaging studies of emotion conducted in healthy volunteers, in order to assess the viability of existing neuroscientific accounts of emotion and, specifically, their ability to account for recent and relevant human brain-mapping data. Thus, by combining data obtained from a wide range of emotion studies, studies that targeted different emotion conditions and employed a variety of experimental paradigms, we investigated the degree to which neural systems were associated with general emotional processing, different emotion dimensions, or distinct affect program emotions. Below, we will present in more detail the findings of this meta-analysis and consider their implications for single-, dual-, and multisystem models of human emotion.

\section{Limbic System Theory of Emotion}

The earliest and most prominent neuroscientific theory of emotion is MacLean's $(1949,1952)$ limbic system theory, which proposed a specialized group of neural structures working collectively to form a unitary emotion system (albeit comprised of three major subdivisions; MacLean, 1993). This theory does receive limited sup-

Table 5

Means $(M)$ and Standard Deviations of $x$-, $y$-, and $z$-Coordinates (Montreal Neurological Institute) for Neural Regions Most Consistently Activated by Each of the Affect Program Emotions

\begin{tabular}{|c|c|c|c|c|c|c|c|}
\hline & \multirow[b]{2}{*}{$\mathrm{L} / \mathrm{R}$} & \multicolumn{2}{|c|}{$x$} & \multicolumn{2}{|c|}{$y$} & \multicolumn{2}{|c|}{$z$} \\
\hline & & $M$ & $S D$ & $M$ & $S D$ & $M$ & $S D$ \\
\hline \multirow[t]{2}{*}{ Fear-amygdala } & $\mathrm{L}$ & -24 & \pm 8 & -6 & \pm 4 & -17 & \pm 7 \\
\hline & $\mathrm{R}$ & 19 & \pm 5 & -8 & \pm 6 & -18 & \pm 6 \\
\hline \multirow[t]{2}{*}{ Disgust-insula/operculum } & $\mathrm{L}$ & -37 & \pm 3 & 5 & \pm 8 & 4 & \pm 8 \\
\hline & $\mathrm{R}$ & 39 & \pm 5 & -5 & \pm 11 & 5 & \pm 6 \\
\hline \multirow[t]{2}{*}{ Disgust-globus pallidus } & $\mathrm{L}$ & \multicolumn{2}{|c|}{-} & \multicolumn{2}{|c|}{-} & \multicolumn{2}{|c|}{-} \\
\hline & $\mathrm{R}$ & 19 & \pm 5 & -6 & \pm 9 & 0 & \pm 6 \\
\hline \multirow[t]{2}{*}{ Anger-lateral OFC } & L & -38 & \pm 12 & 27 & \pm 7 & -8 & \pm 6 \\
\hline & $\mathrm{R}$ & 40 & & 38 & & -12 & \\
\hline \multirow[t]{2}{*}{ Happiness-RSACC/DMPFC } & $\mathrm{L}$ & -6 & \pm 6 & 40 & \pm 8 & 23 & \pm 13 \\
\hline & $\mathrm{R}$ & 5 & \pm 3 & 45 & \pm 4 & 22 & \pm 11 \\
\hline \multirow[t]{2}{*}{ Sadness-RSACC/DMPFC } & $\mathrm{L}$ & -6 & \pm 5 & 44 & \pm 5 & 26 & \pm 10 \\
\hline & $\mathrm{R}$ & 9 & \pm 7 & 43 & \pm 4 & 28 & \pm 13 \\
\hline
\end{tabular}

Note-Midline $(x=0)$ coordinates were excluded from these analyses. L, left; R, right; OFC, orbitofrontal cortex; RSACC, rostral supracallosal anterior cingulate cortex; DMPFC, dorsomedial prefrontal cortex. 
port in the present study in that many of the structures MacLean considered to be important for emotion were activated (e.g., the amygdala and the ACC), although not necessarily in line with predictions from MacLean's model. It is rather striking that many non-"limbic" areas were activated as well (e.g., the basal ganglia and the cerebellum). Indeed, one of the most important findings to emerge in this meta-analysis was the remarkably widespread pattern of neural activity associated with emotion processing. Although one could argue that the wide range of emotional stimuli, tasks, and paradigms adopted by individual studies might be expected to produce such a distributed network of neural activity, it should be emphasized that only those studies employing carefully chosen neutral baseline conditions were included in this meta-analysis. Thus, it is very unlikely that the extensive pattern of neural activity associated with emotion in general can be understood simply in terms of the diverse assortment of tasks used to study this process, especially given the remarkable degree of selectivity and specificity associated with certain emotions superimposed upon this distributed system of brain activity, as will be discussed below.

\section{Right-Hemisphere Hypothesis of Emotion}

Other investigators have argued, on the basis of extensive neuropsychological research conducted in braindamaged individuals, that the RH (and the posterior region in particular) is critically important in the neural representation of emotion (Adolphs et al., 1996; Borod et al., 1998; Borod et al., 2001; Heller et al., 1998). As with the limbic system model, this single-system model did not receive convincing support in the present analysis of all the studies targeting emotional processes, since approximately equivalent numbers of left- and rightsided maxima were observed. Importantly, this finding emerged despite the predominance of studies targeting negative or withdrawal-related emotions, refuting the idea that the RH might be specialized for the processing of highly arousing, unpleasant emotions (Adolphs, Russell, \& Tranel, 1999).

A further refinement of the RH model posits that RH function is more important for the perception of emotion than for the experience and production or expression of emotion (Adolphs et al., 1996; Borod et al., 1998; Borod et al., 2001; Heller et al., 1998). We conducted a more focused analysis of only those neuroimaging studies employing facial expressions of emotion, in order to assess this hypothesis directly. Once again, the results of these analyses failed to demonstrate a critical role for the $\mathrm{RH}$ in the perception of emotion and, instead, revealed approximately equivalent numbers of activation maxima in the $\mathrm{LH}$ and the $\mathrm{RH}$ for both anterior and posterior brain regions.

\section{Dual-System Models of Emotion}

Valence and action tendency. A distinction has been drawn between positive and negative emotions at both psychological and neural levels of explanation. For ex- ample, the valence asymmetry hypothesis (Davidson, 1984) argues for differential involvement of left and right brain regions in positive and negative emotions, respectively - a relationship considered to be particularly pronounced for anterior brain regions. We first tested for a difference in the 3-D distributions of neural activity associated with positive and negative emotions, only to confirm the null hy pothesis of no difference between the two conditions. We then conducted a more focused test of the pooled data set by comparing the total numbers of left- and right-sided activation foci for the positive versus the neutral emotions and the negative versus the neutral emotions contrasts. This combined analysis of the pooled data provided little support for the valence asymmetry hypothesis: The pattern of neural activity associated with both positive and negative emotions was found to be relatively symmetrical.

The lack of support obtained for this model is perhaps unsurprising, given the differences in motivational direction, or action tendency, that have been assigned to different emotions. For example, sadness, although a negative emotion, is thought to be associated with a reduction in the approach motivational system (Henriques \& Davidson, 2000; Henriques, Glowacki, \& Davidson, 1994; Lane, Reiman, Ahern, et al., 1997). Anger, although also negative, is associated with a tendency to approach the stimulus that is inducing this emotion (HarmonJones \& Allen, 1998; Harmon-Jones \& Sigelman, 2001; Heilman, 1997). It has been suggested that consideration of emotion in terms of its associated action tendencies (approach or withdrawal/avoidance) may be much more profitable than a classification based on valence, at least in terms of its predictive power in the field of affective neuroscience (Cacioppo, Gardner, \& Berntson, 1999; Davidson, 1998; Heilman, 1997; Lang et al., 1997). This hypothesis received some support in the analysis of our pooled data set, since the KS3 test demonstrated distinct 3-D distributions of activation foci for approach and withdrawal emotions. However, only partial support was found in the hemispheric analysis, with greater left- than right-sided activity observed for approach-related emotions and symmetrical activity observed for withdrawalrelated emotions. At a finer grain of analysis, greater leftthan right-sided activity was observed for both happiness and anger. Interestingly, asymmetry effects were restricted to anterior brain regions only when these affect program emotions were considered separately.

Other theorists have considered the neurobiological substrates of approach and withdrawal (Cloninger, 1987; J. Gray, 1982; Kinsbourne, 1978; Lang et al., 1990; Schneirla, 1959), although such models are not readily amenable to testing with the present data set. Although the precise substrates differ according to the particular theoretical position, the idea that approach and withdrawal emotion-motivation systems rely on different brain systems is a common theme-a concept that receives some support in the present study. On a slightly different note, Buck $(1999,2002)$ has suggested that a distinction between prosocial and selfish motivations 
may be necessary to explain hemispheric differences in brain activity associated with emotion, although other investigators have argued that this distinction is unlikely to extend hemispheric models of experienced emotion in any meaningful way (J. R. Gray, 2002). In any case, one could argue that classifying emotions in general on the basis of their associated action tendencies might not be entirely productive, even though it might be useful for particular emotions. First, this classification applies to only some emotions and, so, cannot be used as a general emotion taxonomy. Second, it is not always clear how one should go about classifying emotions into one category or the other. For example, although fear is associated with withdrawal, it is also associated with approach to safe places (Blanchard \& Blanchard, 1994). Another potential difficulty is that action tendencies may be overly inclusive, encompassing a number of behaviors that are distinct from the emotions - that is, it cannot distinguish between analogy (common function) and homology (common origin; Griffiths, 1997).

There are further explanations for why asymmetry models (Davidson, 1998; Davidson \& Irwin, 1999) received only partial support in the present study; it is possible that the majority of studies have confounded emotional valence (or action tendency) and arousal or that different methodologies (e.g., EEG vs. neuroimaging) may differ in their sensitivity for detecting laterality differences. An alternate possibility is that our database included studies in which the perception and experience of emotion were investigated. Davidson (1998) has argued that the valence (or action tendency) model applies to experienced emotion or differences in affective style and that resting brain asymmetries predispose people to respond in certain ways to emotional stimuli or events. Given that the experience of emotion is heterogeneous and takes multiple forms (Lambie \& Marcel, 2002), it is not entirely clear how emotion experience should be operationally defined in the context of meta-analysis. Furthermore, it appears that the perception/recognition of emotions in others is dependent on the experience of that affect in the viewer, as supported by paired emotion recognition-experience deficits (Lawrence \& Calder, in press). It is further possible that the laterality effects that have emerged primarily in EEG research, lesion studies, and brain-based behavioral studies reflect asymmetric brain function at a finer level of analysis. Each cerebral hemisphere, or indeed frontal lobe, is a large neural region that supports a wide range of cognitive functions. Thus, it does not seem unreasonable to speculate that the asymmetries demonstrated in EEG, lesion, and behavioral studies may be due to underlying asymmetries of more specialized regions of the brain. Given the absence of a priori hypotheses concerning the precise location of such a relationship, however, we did not feel that a largely post hoc and exploratory analysis of our data on a region-by-region basis was warranted. It is additionally possible that such asymmetries may not be a general phenomenon of all emotions but might, instead, be specific to particular ones, an issue addressed above.

The visual cortex and emotional arousal. It has been suggested that arousal might not be mediated by a particular neural structure but may, instead, be related to the overall state or level of neural system activity (Lang et al., 1998). For example, one important influence of emotional arousal is on the functioning of primary and secondary visual processing areas-areas that act upon visual stimuli at a relatively early stage of perceptual processing. This posited association between emotional stimulus material and activity of early perceptual areas received support in the present study. Activity of the visual cortex was reported in almost $50 \%$ of studies targeting the different discrete emotions, when compared with matched neutral conditions. In addition, the temporal cortex (due to the fusiform gyrus, in many cases) was active in a significant proportion of the studies. This hypothesis receives further support in the substantially greater number of posterior than anterior maxima reported for each of our emotion conditions (see Table 2). One criticism that has been leveled against the suggestion that motivational centers may act to enhance early processing following initial identification of appetitive or aversive stimuli is that the emotional stimuli are often more complex, colorful, and interesting than their neutral counterparts. In the present study, this association held for emotional versus neutral facial expressions as well, suggesting that this is the case even for stimuli that were perceptually matched. According to a biased competition view of attention (Desimone \& Duncan, 1995), heightened visual cortex activity for emotional stimuli would give them a competitive advantage in information processing.

\section{Affect Program Emotions and Regional Specialization}

As was noted above, there was clear evidence to support the presence of separate spatial distributions associated with each of the following affect program emotions: fear, disgust, and anger. In contrast, no significant difference was found between the spatial distributions associated with happiness and sadness. These findings were complemented by a demonstration of relatively distinct emotionregion pairings for the emotions of fear, disgust, and anger, but common regions for happiness and sadness. Importantly, the findings that emerged in this large-scale analysis of neuroimaging studies mirror quite closely those previously found in neuropsychological studies.

Fear and the amygdala. As was noted above, the present study showed good evidence for regional specialization of three discrete emotions: fear, disgust, and anger. We predicted an association between fear and the amygdala; activity of this neural region was reported in approximately $40 \%$ of all the fear studies and in over $60 \%$ of a subset of the studies that employed facial expressions of emotion as stimuli. Although other neural regions were also active in a substantial proportion of 
fear studies (e.g., the ACC and the OFC), amygdala activity was remarkably selective for fear, with fewer than $20 \%$ of the disgust, anger, happiness, or sadness studies reporting activity of this region (see Figure 3).

The observed association between fear and the amygdala is consistent with the results of lesion and electrophysiological studies conducted in humans and laboratory animals (Calder et al., 2001). In patient studies, for example, lesions of the amygdala have been found to disrupt the recognition of facial signals of fear (Adolphs et al., 1994; Calder et al., 1996), as well as the acquisition and expression of fear responses (Bechara et al., 1995; Labar, Ledoux, Spencer, \& Phelps, 1995). Similarly, in a number of mammals, the amygdala mediates fear responses. Although the amygdala has been shown to be involved in the perception and experience of fear, the precise functional role of this neural region remains a debated issue. Some investigators have identified the amygdala as a general "threat detector" (Amaral, 2002) or "fear module" (Öhman \& Mineka, 2001), whereas other investigators have maintained that the amygdala is not involved specifically in the detection of threat but is associated with emotional arousal more generally (Gainotti et al., 1993; Hamann, Ely, Hoffman, \& Kilts, 2002; Hamann \& Mao, 2002; Heller et al., 1998; Öhman, 1986; Williams et al., 2001). It was not possible to address the latter issue empirically in our meta-analysis, since emotion and arousal were confounded in the majority of studies that compared high-arousal positive or negative stimuli with low-arousal neutral stimuli. However, given that anger can be considered a high-arousal emotion (Russell, 1980) and that the amygdala was active in a very small proportion of the anger studies, it seems reasonable to conclude that the amygdala may be more specifically involved in fear processing than in processing the arousal component of emotional stimuli. Clearly, an important goal for future neuroimaging studies of emotion should be to vary emotional arousal while holding emotional valence constant, so that this long-standing debate can be addressed and the precise functional role of the amygdala can be determined.

Disgust and the insula/globus pallidus. A similar level of specificity was demonstrated in studies targeting disgust, as is shown by the results of the KS3 analysis. Specifically, the 3-D distribution of activation foci for disgust differed not only from that associated with fear, but also from those associated with anger, happiness, and sadness. The insula, in particular, was active in over $70 \%$ of the disgust studies, but in fewer than $40 \%$ of the studies targeting each of the other discrete emotions. The globus pallidus was also active in over $70 \%$ of the disgust studies, but in fewer than $25 \%$ of the studies targeting the other affect program emotions. Although considerably fewer studies have addressed the neurobiology of disgust, relative to that of fear, it is important to note that in our more focused analysis of only those studies employing facial expressions of disgust, both the insula and the globus pallidus were active in four and five (out of five) studies that targeted this emotion, respectively.

As for fear, there is a very close correspondence between the regions specified in neuroimaging studies of disgust and those identified in patient-based studies. The basal ganglia, in particular, has been assigned an important role in the recognition of disgust on the basis of studies of patients with Huntington's disease (HD), a neurogenetic disorder affecting the basal ganglia in its early stages. It has been shown that HD patients demonstrate a disproportionately severe impairment in recognizing signals of disgust (J. M. Gray et al., 1997; Sprengelmeyer et al., 1996; Sprengelmeyer et al., 1997). Furthermore, a recent case study of N.K., a patient with a known focal lesion of the basal ganglia and the insula, showed a highly selective deficit in both facial and vocal expressions of disgust, together with atypical reported experience of this emotion (Calder et al., 2000). Involvement of the insula in processing disgust is especially interesting given this region's documented role in gustatory function (Pritchard, Macaluso, \& Eslinger, 1999; Small et al., 1999) and Rozin and colleagues' suggestion that disgust has arisen from a more primitive distaste system (Rozin \& Fallon, 1987; Rozin, Lowery, \& Ebert, 1994). In rats, lesions to the homologous region of the gustatory insula disrupt the distaste response (Kiefer \& Orr, 1992), as do lesions of the globus pallidus (Hernadi, Karadi, Faludi, \& Lenard, 1997).

Anger and the lateral OFC. In studies targeting anger, lateral OFC activity was reported in a higher proportion of studies of anger, relative to other emotions. This distinction between the neural systems involved in anger and fear argues against the idea that there is a neural system specialized for the processing of highly arousing, unpleasant emotions, of which fear and anger are two exemplars (Adolphs, Russell, \& Tranel, 1999). This result is consistent with recent evidence indicating that focal lateral OFC lesions may be specifically associated with changes in aggressive behavior in humans (Blair, 2001; Blair \& Cipolotti, 2000; Brower \& Price, 2001). Similarly, comparative studies have demonstrated alterations in aggressive behavior following lateral OFC lesions in different species of monkey (Butter \& Snyder, 1972; Kamback, 1973; Raleigh, Steklis, Ervin, Kling, \& McGuire, 1979).

\section{A General Role for Anterior Cingulate and Medial Prefrontal Cortices in Emotion}

Whereas some neural regions demonstrated a relative specialization for the discrete emotions of fear, disgust, and anger, as was discussed above, others appeared to play a much more general role in coding for a number of emotions. Indeed, the 3-D distributions of neural activity for happiness and sadness were not found to differ significantly, with the rostral supracallosal ACC/dorsomedial PFC most consistently activated for studies targeting these two emotions. Importantly, this neural re- 
gion was also active in a significant proportion of studies targeting the other discrete emotions.

An important issue raised by this finding is whether there are certain cognitive or affective processes, common to a range of emotions, that are mediated by the ACC or medial prefrontal regions. In contrast to the within-function approach typically adopted in neuroimaging studies, this type of cross-function approach has been advocated by a number of investigators in order to specify why the same brain region is recruited by different conditions (Cabeza \& Nyberg, 2002). Such an approach has proved enormously successful in the work of Duncan and Owen (2000), in which common regions of the PFC were engaged for a broad range of task demands. This finding subsequently led to the development of the adaptive-coding model (Duncan, 2001), indicating that a similar approach could fruitfully be applied to help constrain and generate theories of general processes in affect.

It is certainly the case that data from patient studies (Damasio, 1994; Hornak, Rolls, \& Wade, 1996; Keane, Calder, Hodges, \& Young, 2002; Rolls, 1999) emphasize an important role for the frontal lobes (including the ACC) in processing emotional cues in general. For example, MacLean (1993; see also Lane, Reiman, Ahern, et al., 1997) considered emotion experience to be mediated by the ACC, Damasio (1994) has focused on the contribution of the ventromedial PFC to emotion, Rolls (1999) has posited a general role for the OFC in emotion, and others have suggested that the systems involved in coding individual emotions may feed into more general emotion systems in the frontal cortex (Sprengelmeyer, Rausch, Eysel, \& Przuntek, 1998). If this is correct, we would expect to see general emotion recognition and experience impairments following frontal cortex damage, which appears to be the case (Damasio, Tranel, \& Damasio, 1990; Hornak et al., 1996; Keane et al., 2002).

Before proceeding, it should be noted that the present findings show some correspondence but also striking differences to those reported in another recent metaanalysis of 55 emotion studies (Phan, Wager, Taylor, \& Liberzon, 2002). Both studies show a reliable and specific association between (1) fear and the amygdala and (2) disgust and the basal ganglia, although the present study showed a similar level of insula involvement for the latter emotion. Where these two studies begin to diverge is in their findings for happiness and sadness. Phan et al. found that the basal ganglia, in addition to playing an important role in disgust, were consistently activated for happiness too. This finding contrasts with the association between happiness and the rostral supracallosal ACC reported here, although ACC activity was not restricted to this emotion and was, instead, active across the full range; nor was the association between sadness specific to the subgenual region, but was, as for happiness, most consistently activated in the rostral supracallosal ACC. The present study also obtained an important association between anger and the lateral OFC, an asso- ciation not reported in this earlier study. We offer two possible explanations for the above discrepancies. First, the present study restricted its analysis to only those studies that had a carefully controlled neutral baseline condition, whereas the earlier study did not. Second, the present findings were based on a much larger sample of 106 studies. Although the increased power resulting from this feature of the present study would not be expected to make a substantial difference for the category of fear, which contained 30 studies, it might be expected to change the pattern of findings associated with categories containing a smaller number of studies, such as happiness or anger. The present study further substantiates differences in the patterns of neural activity associated with (1) approach and withdrawal and (2) the affect program emotions through its application of the objective $\mathrm{KS} 3$ test.

\section{Limitations of This Meta-Analysis}

In the introduction, we argued that a major strength of function-location meta-analysis is that inclusion of information on large numbers of participants provides the experimenter with tremendous statistical power. In a way that is not possible in any single neuroimaging study, meta-analysis allows the investigator to identify neural regions that are recruited across different emotion conditions and to view the entire "landscape" of emotion studies. As with most research methods, however, metaanalysis suffers from a number of important limitations, and the present study is no exception. A potential shortcoming of the present meta-analysis is that adoption of a rather coarse classification scheme (valence, action tendency, and discrete emotions) means that, within each of these categories, a wide array of experimental paradigms were used. This raises the possibility that differences in brain regions associated with different emotion conditions could, in fact, be due to differences in the paradigms used to study them. Although the present study did not investigate the effects of specific paradigms on patterns of brain activity directly, it can be seen from Table 1 that a wide variety of paradigms has been used in each of the emotion conditions. Furthermore, this issue has been addressed explicitly in previous meta-analytic work (Phan et al., 2002); however, the brain regions found to be specifically associated with any particular paradigm or emotion induction method in that study are not the same regions as those observed here. The only possible exception was the ACC, which was found by Phan and colleagues to be associated with autobiographical recall. In the present study, the ACC was active across a range of discrete emotions, suggesting that differences in paradigms across emotion conditions were not driving this effect. Although this aspect of our study can be viewed as a limitation, it can also be seen as a strength. Indeed, our guiding strategy was to examine the extent to which rather abstract classifications can be usefully applied to the understanding of the neural organization across all instances of emotions. 
Another issue to consider in the context of metaanalysis is the extent to which any findings may be due to differences in the degree of smoothing and statistical significance thresholds. These factors do not pose difficulties for asymmetry comparisons, since smoothing and significance levels tend not to change across hemisphere, but should be considered in the context of our KS3 and regional analyses. Although the contribution of significance levels was more difficult to ascertain (different thresholds have frequently been used for different brain regions in the same study), the average size of smoothing filter was not found to differ significantly across the different emotion conditions. This result indicates that the present findings are unlikely to be due to such confounds in our data set. Null results should also be interpreted with caution in meta-analyses of neuroimaging data, although it should be emphasized that this limitation is likely to pose far greater problems for single neuroimaging studies that are compromised by limited statistical power.

Finally, ascribing anatomical labels to coordinates in stereotaxic space is problematic for all imaging studies (Brett et al., 2002). The studies included in the present analysis used different stereotaxic templates (MNI and Talairach), and so a transformation was required to match between templates. This has a potential for inaccuracy (Brett et al., 2002). Anatomical labels were assigned by reference to the Talairach atlas, together with the divisions of the ACC, insula/operculum, and lateral OFC distinctions of Paus et al. (1998; Paus et al., 1996) and Small et al. (1999), respectively. However, a wide range of neuroanatomical variation is known to occur in humans, which is not captured by the use of an atlas derived from a single brain. Future meta-analyses will benefit from the development of a label-based maximum probability atlas of the human brain. Nevertheless, it is encouraging that even our relatively crude labeling method was able to yield rather specific and consistent region-emotion pairings for fear (amygdala), disgust (insula/operculum, globus pallidus), and anger (lateral OFC) that correspond well with lesion data on these emotions and their homologues.

\section{Summary and Overall Conclusions}

It is now possible to return to our guiding question: In what ways have recent FNI studies contributed to our understanding of human emotion? As was noted in the introduction, the degree to which existing single-, dual-, and multisystem models are useful in predicting the neural structure of emotion space was of primary interest.

The widespread distribution of neural activity associated with emotion in general, irrespective of the task or paradigm employed in any individualstudy, suggests that the limbic system theory of emotion cannot account for the whole of neuroimaging data. Similarly, the combined data from extant neuroimaging studies of emotion failed to support a special role for the RH or right posterior regions of the brain in emotion or even emotion perception.
Partial support was demonstrated for dual-system models of emotion processing. A variant of the KolmogorovSmirnov statistic appropriate for 3-D data indicated that although the patterns of neural activity associated with positive and negative emotion do not differ, attempts to delineate discrete neural systems for approach and withdrawal action tendencies are likely to be more promising. At a more refined level of analysis, approach emotions were associated with greater relative left- than right-sided hemisphere activity, whereas neural activity observed for negative and withdrawal emotions was symmetrical. The asymmetry observed for approach emotions was restricted to anterior brain regions only when each affect program emotion was considered separately, with happiness and anger demonstrating a greater number of left- relative to right-sided frontal activations. Together, these findings suggest that the above singleand dual-system theories of structure-function relationships may be too coarse, in terms of both their neural underpinnings and the aspect of emotion under consideration, and that, instead, a more intricate relationship between emotion and regional specialization may obtain.

Arguably, considerable support was found for the affect program accounts of emotion: The distributions of activation foci associated with the emotions of fear, anger, and disgust were significantly different from each other and from happiness and sadness. Furthermore, these emotions were most consistently activated in regions that, when damaged, are associated with selective emotion deficits: fear, the amygdala; disgust, the insula/operculum and the globus pallidus; and anger, the lateral OFC. The distributions for happiness and sadness did not differ, with activations clustered around the supracallosal ACC (and the dorsomedial PFC), an area possibly involved in processing emotion more generally. Although we are not of the opinion that the affect program emotions are represented by entirely distinct neural circuits, it seems reasonable to conclude that the underlying neural systems are separate in part. This interpretation is broadly consistent with approaches to emotion in which at least certain affect program emotions may be represented as distinct psychological and neural systems having clear homologies in other mammals. We think that the imaging data, together with neuropsychological evidence, suggest the existence of particular emotion systems-systems that are isolable, specialized, and internally cohesive and that are involved in (but not necessarily exclusively dedicated to) fear, disgust, and anger. Whether these systems are isomorphic with Ekman's $(1992,1999)$ affect programs is as yet unclear. Certainly, at least at the level of resolution of functional imaging data, there appear to be interesting differences between fear, disgust, and anger, on the one hand, and happiness/sadness, on the other.

The present findings have clear implications for the study of human emotion, emphasizing the utility of meta-analytic techniques in assessing the contribution of neuroimaging investigations to our developing understanding of its neural correlates and in generating new 
hypotheses regarding the brain's role in emotion processing. By combining FNI data across different emotional conditions and experimental paradigms, meta-analysis allows us to overcome many of the shortcomings that are typically associated with any single neuroimaging study. It is our hope that the present findings will be useful in the design of future brain-imaging experiments on the neural basis of human emotions.

\section{REFERENCES}

Note: Asterisks mark studies included in the meta-analysis.

Adolphs, R. (1999). Social cognition and the human brain. Trends in Cognitive Sciences, 3, 469-479.

Adolphs, R, Damasio, H., Tranel, D., \& Damasio, A. R. (1996). Cortical systems for the recognition of emotion in facial expressions. Journal of Neuroscience, 16, 7678-7687.

Adolphs, R., Russell, J. A., \& Tranel, D. (1999). A role for the human amygdala in recognizing emotional arousal from unpleasant stimuli. Psychological Science, 10, 167-171.

Adolphs, R., Tranel, D., Damasio, H., \& Damasio, A. (1994). Impaired recognition of emotion in facial expressions following bilateral damage to the human amygdala. Nature, 372, 669-672.

Adolphs, R., Tranel, D., Hamann, S., Young, A. W., Calder, A. J., Phelps, E. A., Anderson, A., Lee, G. P., \& Damasio, A. R. (1999). Recognition of facial emotion in nine individuals with bilateral amygdala damage. Neuropsychologia, 37, 1111-1117.

Amaral, D. G. (2002). The primate amygdala and the neurobiology of social behavior: Implications for understanding social anxiety. Biological Psychiatry, 51, 11-17.

* Baker, S. C., Frith, C. D., \& Dolan, R. J. (1997). The interaction between mood and cognitive function studied with PET. Psychological Medicine, 27, 565-578.

* Bartels, A., \& ZeKI, S. (2000). The neural basis of romantic love. NeuroReport, 11, 3829-3834.

* Beauregard, M., Chertkow, H., Bub, D., Murtha, S., Dixon, R. \& Evans, A. (1997). The neural substrate for concrete, abstract, and emotional word lexica: A positron emission tomography study. Journal of Cognitive Neuroscience, 9, 441-461.

* Beauregard, M., Leroux, J. M., Bergman, S., Arzoumanian, Y., Beaudoin, G., Bourgouin, P., \& Stip, E. (1998). The functional neuroanatomy of major depression: An fMRI study using an emotional activation paradigm. NeuroReport, 9, 3253-3258.

Bechara, A., Tranel, D., Damasio, H., Adolphs, R, Rockland, C., \& Damasio, A. R. (1995). Double dissociation of conditioning and declarative knowledge relative to the amygdala and hippocampus in humans. Science, 269, 1115-1118.

BLAIR, R. J. R. (2001). Neurocognitive models of aggression, the antisocial personality disorders, and psychopathy. Journal of Neurology, Neurosurgery, \& Psychiatry, 71, 727-731.

Blair, R. J. R., \& CipolotTI, L. (2000). Impaired social response reversal: A case of "acquired sociopathy." Brain, 123, 1122-1141.

* Blair, R. J. R., Morris, J. S., Frith, C. D., Perrett, D. I., \& Dolan, R. J. (1999). Dissociable neural responses to facial expressions of sadness and anger. Brain, 122, 883-893.

Blanchard, R. J., \& Blanchard, D. C. (1994). Opponent environmental targets and sensorimotor systems in aggression and defence. In S. J. Cooper \& C. A. Hendrie (Eds.), Ethology and psychopharmacology (pp. 133-157). Chichester, U.K.: Wiley.

* Blood, A. J., \& Zatorre, R. J. (2001). Intensely pleasurable responses to music correlate with activity in brain regions implicated in reward and emotion. Proceedings of the National Academy of Sciences, 98, 11818-11823.

* Blood, A. J., Zatorre, R. J., Bermudez, P., \& Evans, A. C. (1999). Emotional responses to pleasant and unpleasant music correlate with activity in paralimbic brain regions. Nature Neuroscience, 2, 382-387.

Borod, J. C., Cicero, B. A., Obler, L. K., Welkowitz, J., Erhan, H. M., Santschi, C., Grunwald, I. S., Agosti, R. M., \& Whalen, J. R. (1998). Right hemisphere emotional perception: Evidence across multiple channels. Neuropsychology, 12, 446-458.
Borod, J. C., Zgaljardic, D., Tabert, M. H., \& Koff, E. (2001). Asymmetries of emotional perception and expression in normal adults. In G. Gainotti (Ed.), Handbook of neuropsychology (2nd ed., Vol. 5, pp. 181-205). Amsterdam: Elsevier.

* Breiter, H. C., Etcoff, N. L., Whalen, P. J., Kennedy, W. A., Rauch, S. L., Buckner, R. L., Strauss, M. M., Hyman, S. E., \& Rosen, B. R. (1996). Response and habituation of the human amygdala during visual processing of facial expression. Neuron, 17, 875887.

* Bremner, J. D., Narayan, M., Staib, L. H., Southwick, S. M., McGlashan, T., \& Charney, D. S. (1999). Neural correlates of memories of childhood sexual abuse in women with and without posttraumatic stress disorder. American Journal of Psychiatry, 156, 1787-1795.

* Bremner, J. D., Staib, L. H., Kaloupek, D., Southwick, S. M., Soufer, R., \& Charney, D. S. (1999). Neural correlates of exposure to traumatic pictures and sound in Vietnam combat veterans with and without posttraumatic stress disorder: A positron emission tomography study. Biological Psychiatry, 45, 806-816.

Brett, M., Christoff, K., Cusack, R., \& Lancaster, J. (2001). Using the Talairach atlas with the MNI template. NeuroImage, 13, S85.

Brett, M., Johnsrude, I. S., \& Owen, A. M. (2002). The problem of functional localization in the human brain. Nature Reviews Neuroscience, 3, 243-249.

Brower, M. C., \& Price, B. H. (2001). Neuropsychiatry of frontal lobe dysfunction in violent and criminal behaviour: A critical review. Journal of Neurology, Neurosurgery, \& Psychiatry, 71, 720-726.

* Buchanan, T. W., Lutz, K., Mirzazade, S., Specht, K., Shah, N. J., ZiLles, K., \& JÄNCKE, L. (2000). Recognition of emotional prosody and verbal components of spoken language: An fMRI study. Cognitive Brain Research, 9, 227-238.

* Büchel, C., Dolan, R. J., Armony, J. L., \& Friston, K. J. (1999). Amygdala-hippocampal involvement in human aversive trace conditioning revealed through event-related functional magnetic resonance imaging. Journal of Neuroscience, 19, 10869-10876.

* Büchel, C., Morris, J., Dolan, R. J., \& Friston, K. J. (1998). Brain systems mediating aversive conditioning: An event-related fMRI study. Neuron, 20, 947-957.

Buck, R. (1999). The biological affects: A typology. Psychological Review, 106, 301-336.

Buck, R. (2002). The genetics and biology of true love: Prosocial biological affects and the left hemisphere. Psychological Review, 109, 739-744.

Butter, C. M., \& SNyder, D. R. (1972). Alterations in aversive and aggressive behaviors following orbital frontal lesions in rhesus monkeys. Acta Neurobiologiae Experimentalis, 32, 525-565.

* Bystritsky, A., Pontillo, D., Powers, M., Sabb, F. W., Craske, M. G., \& Bookheimer, S. Y. (2001). Functional MRI changes during panic anticipation and imagery exposure. NeuroReport, 12, 3953-3957.

CAbeza, R, \& Ny berg, L. (2000). Imaging cognition: II. An empirical review of 275 PET and fMRI studies. Journal of Cognitive Neuroscience, 12, 1-47.

CABEzA, R., \& Nyberg, L. (2002). Seeing the forest through the trees: The cross-function approach to imaging cognition. In A. Zani \& A. M. Proverbio (Eds.), The cognitive electrophysiology of mind and brain (pp. 41-68). San Diego: Academic Press.

Cacioppo, J. T., Gardner, W. L., \& Berntson, G. G. (1999). The affect system has parallel and integrative processing components: Form follows function. Journal of Personality \& Social Psychology, 76, 839-855.

* Cahill, L., Haier, R. J., Fallon, J., Alkire, M. T., Tang, C., Keator, D., Wu, J., \& McGaugh, J. L. (1996). Amygdala activity at encoding correlated with long-term, free recall of emotional information. Proceedings of the National Academy of Sciences, 93, 8016-8021.

* Cahill, L., Haier, R. J., White, N. S., Fallon, J., Kilpatrick, L., Lawrence, C., Potkin, S. G., \& Alkire, M. T. (2001). Sex-related difference in amygdala activity during emotionally influenced memory storage. Neurobiology of Learning \& Memory, 75, 1-9. Calder, A. J., Keane, J., Manes, F., Antoun, N., \& Young, A. W. 
(2000). Impaired recognition and experience of disgust following brain injury. Nature Neuroscience, 3, 1077-1078.

Calder, A. J., Lawrence, A. D., \& Young, A. W. (2001). Neuropsychology of fear and loathing. Nature Reviews Neuroscience, $\mathbf{2}$, 352-363.

Calder, A. J., Young, A. W., Rowland, D., Perrett, D. I., Hodges, J. R., \& Etcoff, N. L. (1996). Facial emotion recognition after bilateral amygdala damage: Differentially severe impairment of fear. Cognitive Neuropsychology, 13, 699-745.

* Canli, T., Zhao, Z., Brewer, J., Gabrieli, J. D., \& Cahill, L. (2000). Event-related activation in the human amygdala associates with later memory for individual emotional experience. Journal of Neuroscience, 20, (RC99), 1-5.

Carver, C. S., Sutton, S. K., \& Scheier, M. F. (2000). Action, emotion, and personality: Emerging conceptual integration. Personality \& Social Psychology Bulletin, 26, 741-751.

* Chua, P., Krams, M., Toni, I., Passingham, R. \& Dolan, R. (1999). A functional anatomy of anticipatory anxiety. NeuroImage, 9, 563-571.

Cloninger, C. (1987). A systematic method for clinical description and classif ication of personality variants. Archives of General Psychiatry, 44, 573-588.

Collins, D. L., Neelin, P., Peters, T. M., \& Evans, A. C. (1994). Automatic 3D intersubject registration of MR volumetric data in standardized Talairach space. Journal of Computer Assisted Tomography, 18, 192-205.

* Critchley, H., Daly, E., Phillips, M., Brammer, M., Bullmore, E, Williams, S., Van Amelsvoort, T., Robertson, D., David, A., \& Murphy, D. (2000). Explicit and implicit neural mechanisms for processing of social information from facial expressions: A functional magnetic resonance imaging study. Human Brain Mapping, 9, 93-105.

* Crosson, B., Radonovich, K., Sadek, J. R., Gokcay, D., Bauer, R. M., Fischler, I. S., Cato, M. A., Maron, L., Auerbach, E. J., BRowD, S. R. \& BRIGGS, R. W. (1999). Left-hemisphere processing of emotional connotation during word generation. NeuroReport, 10, 2449-2455.

DAmAsio, A. R. (1994). Descartes' error: Emotion, reason, and the human brain. New York: Avon.

DAmasio, A. R. (1998). Emotion in the perspective of an integrated nervous system. Brain Research Reviews, 26, 83-86.

* Damasio, A. R., Grabowski, T. J., Bechara, A., Damasio, H. Ponto, L. L., Parvizi, J., \& Hichwa, R. D. (2000). Subcortical and cortical brain activity during the feeling of self-generated emotions. Nature Neuroscience, 3, 1049-1056.

Damasio, A. R. Tranel, D., \& Damasio, H. (1990). Individuals with sociopathic behavior caused by frontal damage fail to respond autonomically to social stimuli. Behavioural Brain Research, 41, 81-94.

DARWIN, C. (1872). The expression of the emotions in man and animals. London: John Murray.

DAVIDSON, R. J. (1984). Affect, cognition and hemispheric specialization. In C. E. Izard, J. Kagan, \& R. Zajonc (Eds.), Emotion, cognition and behavior (pp. 320-365). New York: Cambridge University Press.

DAvidson, R. J. (1998). Affective style and affective disorders: Perspectives from affective neuroscience. Cognition \& Emotion, 12, 307-330

Davidson, R. J., Ekman, P., Saron, C. D., Senulis, J. A., \& Friesen, W. V. (1990). Approach-withdrawal and cerebral asymmetry: Emotional expression and brain physiology I. Journal of Personality \& Social Psychology, 58, 330-341.

DAVIDSON, R. J., \& IRWIN, W. (1999). The functional neuroanatomy of emotion and affective style. Trends in Cognitive Sciences, 3, 11-21.

Davidson, R. J., \& SutTon, S. K. (1995). Affective neuroscience: The emergence of a discipline. Current Opinion in Neurobiology, $\mathbf{5}$, 217-224.

Depue, R. A., \& IAcono, W. G. (1989). Neuro-behavioral aspects of affective disorders. Annual Review of Psychology, 40, 457-492.

Desimone, R, \& Duncan, J. (1995). Neural mechanisms of selective visual attention. Annual Review of Neuroscience, 18, 193-222.

DIENER, E. (1999). Introduction to the special section on the structure of emotion. Journal of Personality \& Social Psychology, 76, 803-804.

* Dolan, R. J., Fletcher, P., Morris, J., Kapur, N., Deakin, J. F., \&
FrITH, C. D. (1996). Neural activation during covert processing of positive emotional facial expressions. Neurolmage, 4, 194-200.

* Dolan, R. S., Lane, R. Chua, P., \& Fletcher, P. (2000). Dissociable temporal lobe activations during emotional episodic memory retrieval. NeuroImage, 11, 203-209.

* Dougherty, D. D., Shin, L. M., Alpert, N. M., Pitman, R. K., Orr, S. P., Lasko, M., Macklin, M. L., Fischman, A. J., \& Rauch, S. L. (1999). Anger in healthy men: A PET study using script-driven imagery. Biological Psychiatry, 46, 466-472.

Duncan, J. (2001). An adaptive coding model of neural function in prefrontal cortex. Nature Reviews Neuroscience, 2, 820-829.

Duncan, J., \& Owen, A. M. (2000). Common regions of the human frontal lobe recruited by diverse cognitive demands. Trends in Neurosciences, 23, 475-483.

Ekman, P. (1992). An argument for basic emotions. Cognition \& Emotion, 6, 169-200.

Ekman, P. (1999). Basic emotions. In T. Dalgleish \& M. J. Power (Eds.), Handbook of cognition and emotion (pp. 45-60). Chichester, U.K.: Wiley.

EKMAN, P., \& FRIESEN, W. V. (1982). Measuring facial movement with the Facial Action Coding System. In P. Ekman (Ed.), Emotion in the human face (pp. 178-211). Cambridge: Cambridge University Press.

* Elliott, R. \& Dolan, R. J. (1998). Neural response during preference and memory judgments for subliminally presented stimuli: A functional neuroimaging study. Journal of Neuroscience, 18, 46974704

* Elliott, R, Rubinsztein, J. S., Sahakian, B. J., \& Dolan, R. J. (2000). Selective attention to emotional stimuli in a verbal go/no-go task: An fMRI study. NeuroReport, 11, 1739-1744.

FASANo, G., \& Franceschini, A. (1987). A multi-dimensional version of the Kolmogorov-Smirnov Test. Monthly Notices of the Royal Astronomical Society, 225, 155-170.

* Fischer, H., Andersson, J. L., Furmark, T., \& Fredrikson, M. (2000). Fear conditioning and brain activity: A positron emission tomography study in humans. Behavioral Neuroscience, 114, 671680.

* Fischer, H., Wik, G., \& Fredrikson, M. (1996). Functional neuroanatomy of robbery re-experience: Affective memories studied with PET. NeuroReport, 7, 2081-2086.

Fox, N. A., \& DAVIDSON, R. J. (1986). Smiles to the stranger, joy to the mother: EEG asymmetry discriminates between felt and unfelt smiles in human infants [Abstract]. Psychophysiology, 23, 436.

Fox, P. T., Parsons, L. M., \& Lancaster, J. L. (1998). Beyond the single study: Function/location meta-analysis in cognitive neuroimaging. Current Opinion in Neurobiology, 8, 178-187.

* Francis, S., Rolls, E. T., Bowtell, R., McGlone, F., O'Doherty, J., Browning, A., Clare, S., \& Smith, E. (1999). The representation of pleasant touch in the brain and its relationship with taste and olfactory areas. NeuroReport, 10, 453-459.

* Fredrikson, M., Furmark, T., Olsson, M. T., Fischer, H., AndersSON, J., \& LANGSTROM, B. (1998). Functional neuroanatomical correlates of electrodermal activity: A positron emission tomographic study. Psychophysiology, 35, 179-185.

* Fredrikson, M., WiK, G., Fischer, H., \& Andersson, J. (1995). Affective and attentive neural networks in humans: A PET study of Pavlovian conditioning. NeuroReport, 7, 97-101.

* Frey, S., Kostopoulos, P., \& Petrides, M. (2000). Orbitofrontal involvement in the processing of unpleasant auditory information. European Journal of Neuroscience, 12, 3709-3712.

FriJda, N. H. (1986). The emotions. Cambridge: Cambridge University Press.

Gainotti, G., Caltagirone, C., \& Zoccolotti, P. (1993). Left/right and cortical/subcortical dichotomies in the neuropsychological study of human emotions. Cognition \& Emotion, 7, 71-93.

* Gemar, M. C., Kapur, S., Segal, Z. V., Brown, G. M., \& Houle, S. (1996). Effects of self-generated sad mood on regional cerebral activity: A PET study in normal subjects. Depression, 4, 81-88.

* George, M. S., Ketter, T. A., Parekh, P. I., Gill, D. S., Marangell, L. B., Pazzaglia, P. J., Herscovitch, P., \& Post, R. M. (1997). Depressed subjects have decreased $\mathrm{rCBF}$ activation during facial emotion recognition. CNS Spectrums, 2, 45-55. 
* George, M. S., Ketter, T. A., Parekh, P. I., Herscovitch, P., \& Post, R. M. (1996). Gender differences in regional cerebral blood flow during transient self-induced sadness or happiness. Biological Psychiatry, 40, 859-871.

* George, M. S., Ketter, T. A., Parekh, P. I., Horwitz, B., HerscoVITCH, P., \& Post, R. M. (1995). Brain activity during transient sadness and happiness in healthy women. American Journal of Psychiatry, 152, 341-351.

* George, M. S., Parekh, P. I., Rosinsky, N., Ketter, T. A., Kimbrell, T. A., Heilman, K. M., Herscovitch, P., \& Post, R. M. (1996). Understanding emotional prosody activates right hemisphere regions. Archives of Neurology, 53, 665-670.

* Goel, V., \& Dolan, R. J. (2001). The functional anatomy of humor: Segregating cognitive and affective components. Nature Neuroscience, 4, 237-238.

GRAY, J. (1982). The neuropsychology of anxiety. New York: Oxford University Press.

Gray, J. M., Young, A. W., Barker, W. A., Curtis, A., \& Gibson, D. (1997). Impaired recognition of disgust in Huntington's disease gene carriers. Brain, 120, 2029-2038.

GRAY, J. R. (2002). Does a prosocial-selfish distinction help explain the biological affects? Comment on Buck (1999). Psychological Review, 109, 729-738.

Green, D. P., \& Salovey, P. (1999). In what sense are positive and negative affect independent? A reply to Tellegen, Watson, and Clark. Psychological Science, 10, 304-306.

Griffiths, P. E. (1997). What emotions really are: The problem of psychological categories. Chicago: Chicago University Press.

* Hamann, S. B., Ely, T. D., Grafton, S. T., \& Kilts, C. D. (1999). Amygdala activity related to enhanced memory for pleasant and aversive stimuli. Nature Neuroscience, 2, 289-293.

Hamann, S. B., Ely, T. D., Hoffman, J. M., \& Kilts, C. D. (2002). Ecstasy and agony: Activation of the human amygdala in positive and negative emotion. Psychological Science, 13, 135-141.

Hamann, S. [B.], \& MaO, H. (2002). Positive and negative emotional verbal stimuli elicit activity in the left amygdala. NeuroReport, 13, $15-19$.

* Hariri, A. R., Bookheimer, S. Y., \& Mazziotta, J. C. (2000). Modulating emotional responses: Effects of a neocortical network on the limbic system. NeuroReport, 11, 43-48.

Harmon-Jones, E., \& Allen, J. J. B. (1998). Anger and frontal brain activity: EEG asymmetry consistent with approach motivation despite negative affective valence. Journal of Personality \& Social Psychology, 74, 1310-1316.

Harmon-Jones, E., \& Sigelman, J. (2001). State anger and prefrontal brain activity: Evidence that insult-related relative left-prefrontal activation is associated with experienced anger and aggression. Journal of Personality \& Social Psychology, 80, 797-803.

HeILman, K. M. (1997). The neurobiology of emotional experience. Journal of Neuropsychiatry, 9, 439-448.

Heller, W., \& Nitschke, J. B. (1997). Regional brain activity in emotion: A framework for understanding cognition in depression. Cognition \& Emotion, 11, 637-661.

Heller, W., Nitschke, J. B., \& Miller, G. A. (1998). Lateralization in emotion and emotional disorders. Current Directions in Psychological Science, 7, 26-32.

Henriques, J. B., \& Davidson, R. J. (2000). Decreased responsiveness to reward in depression. Cognition \& Emotion, 14, 711-724.

Henriques, J. B., Glowacki, J. M., \& Davidson, R. J. (1994). Reward fails to alter response bias in depression. Journal of Abnormal Psychology, 103, 460-466.

Hernadi, I., Karadi, K., Faludi, B., \& Lenard, L. (1997). Disturbances of neophobia and taste-aversion learning after bilateral kainate microlesions in the rat pallidum. Behavioral Neuroscience, 111, 137-146.

* Herpetz, S. C., Dietrich, T. M., Wenning, B., Krings, T., Erberich, S. G., Willmes, K., Thron, A., \& SAss, H. (2001). Evidence of abnormal amygdala functioning in borderline personality disorder: A functional MRI study. Biological Psychiatry, 50, 292-298.

Hornak, J., Rolls, E. T., \& Wade, D. (1996). Face and voice ex- pression identification in patients with emotional and behavioural changes following ventral frontal lobe damage. Neuropsychologia, 34, 247-261.

* Hsieh, J. C., Stone-Elander, S., \& Ingvar, M. (1999). Anticipatory coping of pain expressed in the human anterior cingulate cortex: A positron emission tomography study. Neuroscience Letters, 262 , 61-64.

*Hugdahl, K., Berardi, A., Thompson, W. L., Kosslyn, S. M., Macy, R., Baker, D. P., Alpert, N. M., \& LeDoux, J. E. (1995). Brain mechanisms in human classical conditioning: A PET blood flow study. NeuroReport, 6, 1723-1728.

*Iidaka, T., Omori, M., Murata, T., Kosaka, H., Yonekura, Y., OKadA, T., \& Sadato, N. (2001). Neural interaction of the amygdala with the prefrontal and temporal cortices in the processing of facial expressions as revealed by fMRI. Journal of Cognitive Neuroscience, 13, 1035-1047.

* Imaizumi, S., Mori, K., Kiritani, S., Kawashima, R., Sugiura, M., Fukuda, H., Itoh, K., Kato, T., Nakamura, A., Hatano, K., Kojima, S., \& Nakamura, K. (1997). Vocal identification of speaker and emotion activates different brain regions. NeuroReport, 8, 2809-2812.

*Irwin, W., Davidson, R. J., Lowe, M. J., Mock, B. J., Sorenson, J. A., \& TURSKI, P. A. (1996). Human amygdala activation detected with echo-planar functional magnetic resonance imaging. NeuroReport, 7, 1765-1769.

* Isenberg, N., Silbersweig, D., Engelien, A., Emmerich, S., Malavade, K., Beattie, B., Leon, A. C., \& Stern, E. (1999). Linguistic threat activates the human amygdala. Proceedings of the $\mathrm{Na}$ tional Academy of Sciences, 96, 10456-10459.

IzARD, C. E. (1971). The face of emotion. New York: Appleton-CenturyCrofts.

Kalin, N. H., Larson, C., Shelton, S. E., \& Davidson, R. J. (1998). Asymmetric frontal brain activity, cortisol, and behavior associated with fearful temperament in rhesus monkeys. Behavioral Neuroscience, 112, 286-292.

KAMBACK, M. C. (1973). The effects of orbital and dorsolateral frontal cortical ablations on ethanol self-selection and emotional behaviors in monkeys (Macaca nemestrina). Neuropsychologia, 11, 331-335.

Keane, J., Calder, A. J., Hodges, J. R., \& Young, A. W. (2002). Face and emotion processing in frontal variant frontotemporal dementia. Neuropsychologia, 40, 655-665.

* Kesler-West, M. L., Andersen, A. H., Smith, C. D., Avison, M. J., DAVIS, C. E., Kryscio, R. J., \& Blonder, L. X. (2001). Neural substrates of facial emotion processing using fMRI. Brain Research: Cognitive Brain Research, 11, 213-226.

KIEFER, S. W., \& ORR, M. R. (1992). Taste avoidance, but not aversion, learning in rats lacking gustatory cortex. Behavioral Neuroscience, 106, $140-146$.

* Kimbrell, T. A., George, M. S., Parekh, P. I., Ketter, T. A., Podell, D. M., Danielson, A. L., Repella, J. D., Benson, B. E., Willis, M. W., Herscovitch, P., \& Post, R. M. (1999). Regional brain activity during transient self-induced anxiety and anger in healthy adults. Biological Psychiatry, 46, 454-465.

Kinsbourne, M. (1978). Biological determinants of functional bisymmetry and asymmetry. In M. Kinsbourne (Ed.), Asymmetrical function of the brain (pp. 3-13). New York: Cambridge University Press.

* Knutson, B., Adams, C. M., Fong, G. W., \& Hommer, D. (2001). Anticipation of increasing monetary reward selectively recruits nucleus accumbens. Journal of Neuroscience, 21, 1-5.

* Kosslyn, S. M., Shin, L. M., Thompson, W. L., McNally, R. J., Rauch, S. L., Pitman, R. K., \& Alpert, N. M. (1996). Neural effects of visualizing and perceiving aversive stimuli: A PET investigation. NeuroReport, 7, 1569-1576.

* LaBar, K. S., Gatenby, J. C., Gore, J. C., LeDoux, J. E. \& Phelps, E. A. (1998). Human amygdala activation during conditioned fear acquisition and extinction: A mixed-trial fMRI study. Neuron, 20, 937-945.

Labar, K. S., Ledoux, J. E., Spencer, D. D., \& Phelps, E. A. (1995). Impaired fear conditioning following unilateral temporal lobectomy in humans. Journal of Neuroscience, 15, 6846-6855. 
Lambie, J. A., \& Marcel, A. J. (2002). Consciousness and the varieties of emotion experience: A theoretical framework. Psychological Review, 109, 219-259.

Lancaster, J. L., Woldorff, M. G., Parsons, L. M., Liotti, M., Freitas, C. S., Rainey, L., Kochunov, P. V., Nickerson, D., MiTIKEN, S. A., \& Fox, P. T. (2000). Automated Talairach atlas labels for functional brain mapping. Human Brain Mapping, 10, 120-131.

* Lane, R. D., Chua, P. M.-L., \& Dolan, R. J. (1999). Common effects of emotional valence, arousal and attention on neural activation during visual processing of pictures. Neuropsychologia, 37, 989-997.

* Lane, R. D., Reiman, E. M., Ahern, G. L., Schwartz, G. E., \& DAVIDSON, R. J. (1997). Neuroanatomical correlates of happiness, sadness, and disgust. American Journal of Psychiatry, 154, 926933.

* Lane, R. D., Reiman, E. M., Bradley, M. M., Lang, P. J., Ahern, G. L., Davidson, R. J., \& Schwartz, G. E. (1997). Neuroanatomical correlates of pleasant and unpleasant emotion. Neuropsychologia, 35, 1437-1444.

Lang, P. J., Bradley, M. M., \& Cuthbert, B. N. (1990). Emotion, attention, and the startle reflex. Psychological Review, 97, 377-395.

Lang, P. J., Bradley, M. M., \& Cuthbert, B. N. (1997). Motivated attention: Affect, activation, and action. In P. J. Lang, R. F. Simons, \& M. T. Balaban (Eds.), Attention and orienting: Sensory and motivational processes (pp. 97-135). Mahwah, NJ: Erlbaum.

* Lang, P. J., Bradley, M. M., Fitzsimmons, J. R., Cuthbert, B. N., Scott, J. D., Moulder, B., \& NAngia, V. (1998). Emotional arousal and activation of the visual cortex: An fMRI analysis. Psychophysiology, 35, 199-210.

Lawrence, A. D., \& CALder, A. J. (in press). Homologizing human emotions. In D. A. Evans \& P. Cruse (Eds.), Emotions, evolution and rationality. Oxford: Oxford University Press.

Lawrence, A. D., Calder, A. J., McGowan, S. V., \& Grasby, P. M. (2002). Selective disruption of the recognition of facial expressions of anger. NeuroReport, 13, 881-884.

LeDoux, J. E. (1991). Emotion and the limbic system concept. Concepts in Neuroscience, 2, 169-199.

* Liberzon, I., Taylor, S. F., Fig, L. M., Decker, L. R., Koeppe, R. A., \& Minoshima, S. (2000). Limbic activation and psychophysiologic responses to aversive visual stimuli: Interaction with cognitive task. Neuropsychopharmacology, 23, 508-516.

* Liotti, M., Mayberg, H. S., Brannan, S. K., McGinnis, S., JerABEK, P., \& Fox, P. T. (2000). Differential limbic-cortical correlates of sadness and anxiety in healthy subjects: Implications for affective disorders. Biological Psychiatry, 48, 30-42.

* Lorberbaum, J. P., Newman, J. D., Dubno, J. R., Horwitz, A. R., Nahas, Z., Teneback, C. C., Bloomer, C. W., Bohning, D. E., Vincent, D., Johnson, M. R., Emmanuel, N., BrawmanMintzer, O., Book, S. W., Lydiard, R. B., Ballenger, J. C., \& GEORGE, M. S. (1999). Feasibility of using fMRI to study mothers responding to infant cries. Depression \& Anxiety, 10, 99-104.

MacLean, P. D. (1949). Psychosomatic disease and the "visceral brain": Recent developments bearing on the Papez theory of emotion. Psychosomatic Medicine, 11, 338-353.

MacLean, P. D. (1952). Some psychiatric implications of physiological studies on frontotemporal portion of limbic system (visceral brain). Electroencephalography \& Clinical Neurophysiology, 4, 407-418.

MacLean, P. D. (1993). Cerebral evolution of emotion. In M. Lewis \& J. M. Haviland (Eds.), Handbook of emotions (pp. 67-83). New York: Guilford.

MacLean, P. D. (2001). Ongoing discussion of book reviews of Jaak Panksepp (1998), Affective neuroscience. NeuroPsychoanalysis, 3, 81-85.

* Maddock, R. J., \& Buonocore, M. H. (1997). Activation of left posterior cingulate gyrus by the auditory presentation of threat-related words: An fMRI study. Psychiatry Research, 75, 1-14.

Mandal, M. K., Asthana, H. S., Tandon, S. C., \& Asthana, S. (1992). Role of cerebral hemispheres and regions in processing hemifacial expression of emotion: Evidence from brain-damage. International Journal of Neuroscience, 63, 187-195.

Mandal, M. K., Mohanty, A., Pandey, R., \& Mohanty, S. (1996).
Emotion-specific processing deficit in focal brain-damaged patients. International Journal of Neuroscience, 84, 87-95.

* Maratos, E. J., Dolan, R. J., Morris, J. S., Henson, R. N. A., \& RUGG, M. D. (2001). Neural activity associated with episodic memory for emotional context. Neuropsychologia, 39, 910-920.

* Mayberg, H. S., Liotti, M., Brannan, S. K., McGinnis, S., Mahurin, R. K., Jerabek, P. A., Silva, J. A., Tekell, J. L., Martin, C. C., Lancaster, J. L., \& Fox, P. T. (1999). Reciprocal limbiccortical function and negative mood: Converging PET findings in depression and normal sadness. American Journal of Psychiatry, 156, 675-682.

Mendoza, S. P., \& Ruys, J. D. (2001). The beginning of an alternative view of the neurobiology of emotion. Social Science Information, 40, 39-60.

MiLls, C. K. (1912). The cortical representation of emotion, with a discussion of some points in the general nervous system mechanism of expression in its relation to organic nervous disease and insanity. Proceedings of the American Medico-Psychological Association, 19, 297-300.

Moller, A. P., \& Jennions, M. D. (2001). Testing and adjusting for publication bias. Trends in Ecology \& Evolution, 16, 580-586.

* Morris, J. S., Büchel, C., \& Dolan, R. J. (2001). Parallel neural responses in amygdala subregions and sensory cortex during implicit fear conditioning. NeuroImage, 13, 1044-1052.

* Morris, J. S., Friston, K. J., Büchel, C., Frith, C. D., Young, A. W., Calder, A. J., \& Dolan, R. J. (1998). A neuromodulatory role for the human amygdala in processing emotional facial expressions. Brain, 121, 47-57.

* Morris, J. S., Friston, K. J., \& Dolan, R. J. (1997). Neural responses to salient visual stimuli. Proceedings of the National Academy of Sciences, 264, 769-775.

* Morris, J. S., Friston, K. J., \& Dolan, R. J. (1998). Experiencedependent modulation of tonotopic neural responses in human auditory cortex. Proceedings of the National Academy of Sciences, 265, 649-657.

* Morris, J. S., Öhman, A. \& Dolan, R. J. (1998). Conscious and unconscious emotional learning in the human amygdala. Nature, 393, 467-470.

* Morris, J. S., Öhman, A., \& Dolan, R. J. (1999). A subcortical pathway to the right amygdala mediating "unseen" fear. Proceedings of the National Academy of Sciences, 96, 1680-1685.

* Morris, J. S., Scott, S. K., \& Dolan, R. J. (1999). Saying it with feeling: Neural responses to emotional vocalizations. Neuropsychologia, 37, 1155-1163.

* Nakamura, K., Kawashima, R., Ito, K., Sugiura, M., Kato, T., Nakamura, A., Hatano, K., Nagumo, S., Kubota, K., Fukuda, H., \& KoJima, S. (1999). Activation of the right inferior frontal cortex during assessment of facial emotion. Journal of Neurophysiology, 82, 1610-1614.

* Narumoto, J., Yamada, H., Iidaka, T., Sadato, N., Fukui, K., ITOH, H., \& YoneKuRA, Y. (2000). Brain regions involved in verbal or nonverbal aspects of facial emotion recognition. NeuroReport, 11, 2571-2576.

* O’Doherty, J., Rolls, E. T., Francis, S., Bowtell, R., \& McGLONE, F. (2001). Representation of pleasant and aversive taste in the human brain. Journal of Neurophysiology, 85, 1315-1321.

Öhman, A. (1986). Face the beast and fear the face: Animal and social fears as prototypes for evolutionary analyses of emotion. Psychophysiology, 23, 123-145.

Öhman, A., \& MineKa, S. (2001). Fears, phobias, and preparedness: Toward an evolved module of fear and fear learning. Psychological Review, 108, 483-522.

Öngür, D., Ferry, A. T., \& Price, J. L. (2003). Architectonic subdivision of the human orbital and medial prefrontal cortex. Journal of Comparative Neurology, 460, 425-449.

Ortony, A., \& Turner, T. J. (1990). What's basic about basic emotions? Psychological Review, 97, 315-331.

PANKSEPP, J. (2000). Emotions as natural kinds within the mammalian brain. In M. Lewis \& J. M. Haviland-Jones (Eds.), Handbook of emotions (2nd ed., pp. 137-156). New York: Guilford.

* Paradiso, S., Johnson, D. L., Andreasen, N. C., O'Leary, D. S., 
Watkins, G. L., Ponto, L. L., \& Hichwa, R. D. (1999). Cerebral blood flow changes associated with attribution of emotional valence to pleasant, unpleasant, and neutral visual stimuli in a PET study of normal subjects. American Journal of Psychiatry, 156, 1618-1629.

* Paradiso, S., Robinson, R. G., Andreasen, N. C., Downhill, J. E., Davidson, R. J., Kirchner, P. T., Watkins, G. L., Ponto, L. L., \& Hichwa, R. D. (1997). Emotional activation of limbic circuitry in elderly normal subjects in a PET study. American Journal of Psychiatry, 154, 384-389.

* Partiot, A., Grafman, J., Sadato, N., Wachs, J., \& Hallett, M. (1995). Brain activation during the generation of non-emotional and emotional plans. NeuroReport, 6, 1397-1400.

Paus, T., Koski, L., Caramanos, Z., \& Westbury, C. (1998). Regional differences in the effects of task difficulty and motor output on blood flow response in the human anterior cingulate cortex: A review of 107 PET activation studies. NeuroReport, 9, R37-R47.

Paus, T., Tomaiuolo, F., Otaky, N., MacDonald, D., Petrides, M., Atlas, J., Morris, R., \& Evans, A. C. (1996). Human cingulate and paracingulate sulci: Pattern, variability, asymmetry, and probabilistic map. Cerebral Cortex, 6, 207-214.

Phan, K. L., Wager, T., Taylor, S. F., \& Liberzon, I. (2002). Functional neuroanatomy of emotion: A meta-analysis of emotion activation studies in PET and fMRI. NeuroImage, 16, 331-348.

* Phelps, E. A., O' Connor, K. J., Gatenby, J. C., Gore, J. C., GrilLON, C., \& DAvis, M. (2001). Activation of the left amygdala to a cognitive representation of fear. Nature Neuroscience, 4, 437-441.

* Phillips, M. L., Bullmore, E. T., Howard, R., Woodruff, P. W., Wright, I. C., Williams, S. C., Simmons, A., Andrew, C., BramMER, M., \& DAVID, A. S. (1998). Investigation of facial recognition memory and happy and sad facial expression perception: An fMRI study. Psychiatry Research, 83, 127-138.

* Phillips, M. L., Marks, I. M., Senior, C., Lythgoe, D., O’Dwyer, A. M., Meehan, O., Williams, S. C. R., Brammer, M. J., Bullmore, E. T., \& McGuire, P. K. (2000). A differential neural response in obsessive-compulsive disorder patients with washing compared with checking symptoms to disgust. Psychological Medicine, 30, 1037-1050.

* Phillips, M. L., Williams, L., Senior, C., Bullmore, E. T., Brammer, M. J., Andrew, C., Williams, S. C., \& David, A. S. (1999). A differential neural response to threatening and non-threatening negative facial expressions in paranoid and non-paranoid schizophrenics. Psychiatry Research, 92, 11-31.

* Phillips, M. L., Young, A. W., Scott, S. K., Calder, A. J., Andrew, C., Giampietro, V., Williams, S. C. R, Bullmore, E. T., Brammer, M., \& GraY, J. A. (1998). Neural responses to facial and vocal expressions of fear and disgust. Proceedings of the Royal Society of London: Series B, 265, 1809-1817.

* Phillips, M. L., Young, A. W., Senior, C., Brammer, M., Andrew, C., Calder, A. J., Bullmore, E. T., Perrett, D. I., Rowland, D., Williams, S. C., Gray, J. A., \& David, A. S. (1997). A specific neural substrate for perceiving facial expressions of disgust. $\mathrm{Na}$ ture, 389, 495-498.

* Pietrini, P., Guazzelli, M., Basso, G., Jaffe, K., \& Grafman, J. (2000). Neural correlates of imaginal aggressive behavior assessed by positron emission tomography in healthy subjects. American Journal of Psychiatry, 157, 1772-1781.

* Ploghaus, A., Tracey, I., Gati, J. S., Clare, S., Menon, R. S., Matthews, P. M., \& Rawlins, J. N. (1999). Dissociating pain from its anticipation in the human brain. Science, 284, 1979-1981.

PraestgaARd, J. (1995). Permutation and bootstrap KolmogorovSmirnov tests for the equality of two distributions. Scandinavian Journal of Statistics: Theory \& Applications, 22, 305-322.

Pritchard, T. C., Macaluso, D. A., \& Eslinger, P. J. (1999). Taste perception in patients with insular cortex lesions. Behavioral Neuroscience, 113, 663-671.

* Rainville, P., Duncan, G. H., Price, D. D., Carrier, B., \& Bushnell, M. C. (1997). Pain affect encoded in human anterior cingulate but not somatosensory cortex. Science, 277, 968-971.

Raleigh, M. J., Steklis, H. D., Ervin, F. R., Kling, A. S., \& McGuire, M. T. (1979). The effects of orbitofrontal lesions on the aggressive behavior of Vervet monkeys (Cercopithecus aethiops sabaeus). Experimental Neurology, 66, 158-168.

* Rauch, S. L., Shin, L. M., Dougherty, D. D., Alpert, N. M., Orr, S. P., Lasko, M., Macklin, M. L., Fischman, A. J., \& Pitman, R. K. (1999). Neural activation during sexual and competitive arousal in healthy men. Psychiatry Research, 91, 1-10.

* Reiman, E. M., Lane, R. D., Ahern, G. L., Schwartz, G. E., Davidson, R. J., Friston, K. J., Yun, L. S., \& Chen, K. (1997). Neuroanatomical correlates of externally and internally generated human emotion. American Journal of Psychiatry, 154, 918-925.

REINER, A. (1990). The triune brain in evolution: Role in paleocerebral functions-MacLean, P. D. Science, 250, 303-305.

Robinson, R. G., \& MANES, F. (2000). Elation, mania, and mood disorders: Evidence from neurological disease. In J. C. Borod (Ed.), The neuropsychology of emotion (pp. 239-268). Oxford: Oxford University Press.

Rolls, E. T. (1999). The brain and emotion. Oxford: Oxford University Press.

* Royet, J. P., Hudry, J., Zald, D. H., Godinot, D., Gregoire, M. C., Lavenne, F., Costes, N., \& Holley, A. (2001). Functional neuroanatomy of different olfactory judgments. NeuroImage, 13, 506-519.

* Royet, J. P., Zald, D., Versace, R., Costes, N., Lavenne, F., Koenig, O., \& Gervais, R. (2000). Emotional responses to pleasant and unpleasant olfactory, visual, and auditory stimuli: A positron emission tomography study. Journal of Neuroscience, 20 , 7752-7759.

Rozin, P., \& Fallon, A. E. (1987). A perspective on disgust. Psychological Review, 94, 23-41.

Rozin, P., Lowery, L., \& EBERT, R. (1994). Varieties of disgust faces and the structure of disgust. Journal of Personality \& Social Psychology, 66, 870-881.

Russell, J. A. (1980). A circumplex model of affect. Journal of Personality \& Social Psychology, 39, 1161-1178.

Russell, J. A., \& Barrett, L. F. (1999). Core affect, prototypical emotional episodes, and other things called emotion: Dissecting the elephant. Journal of Personality \& Social Psychology, 76, 805-819.

Russell, J. A., \& Bullock, M. (1985). Multidimensional-scaling of emotional facial expressions: Similarity from preschoolers to adults. Journal of Personality \& Social Psychology, 48, 1290-1298.

Sackeim, H. A., Greenberg, M. S., Weiman, A. L., Gur, R. C., Hungerbuhler, J. P., \& Geschwind, N. (1982). Hemispheric asymmetry in the expression of positive and negative emotions: Neurologic evidence. Archives of Neurology, 39, 210-218.

SACKEIM, H. A., \& GUR, R. E. (1978). Emotions are expressed more intensely on the left side of the face. Science, 202, 434-436.

* Sawamoto, N., Honda, M., OKada, T., Hanakawa, T., Kanda, M., Fukuyama, H., Konishi, J., \& Shibasaki, H. (2000). Expectation of pain enhances responses to nonpainful somatosensory stimulation in the anterior cingulate cortex and parietal operculum/posterior insula: An event-related functional magnetic resonance imaging study. Journal of Neuroscience, 20, 7438-7445.

Schmidt, L. A., \& Schulkin, J. (2000). Toward a computational affective neuroscience. Brain \& Cognition, 42, 95-98.

Schmolck, H., \& Seuire, L. (2001). Impaired perception of facial emotions following bilateral damage to the anterior temporal lobe. Neuropsychology, 15, 30-38.

SchneIrla, T. (1959). An evolutionary and developmental theory of biphasic processes underlying approach and withdrawal. In M. Jones (Ed.), Nebraska Symposium on Motivation (pp. 1-42). Lincoln: University of Nebraska Press.

Schwartz, G. E., Davidson, R. J., \& Maer, F. (1975). Right hemisphere lateralization for emotion in the human brain: Interactions with cognition. Science, 190, 286-288.

* Sergent, J., Ohta, S., MacDonald, B., \& Zuck, E. (1994). Segregated processing of facial identity and emotion in the human brain: A PET study. Visual Cognition, 1, 349-369.

* Shin, L. M., Dougherty, D. D., OrR, S. P., Pitman, R. K., Lasko, M., Macklin, M. L., Alpert, N. M., Fischman, A. J., \& Rauch, S. L. (2000). Activation of anterior paralimbic structures during guiltrelated script-driven imagery. Biological Psychiatry, 48, 43-50. 
* Shin, L. M., Kosslyn, S. M., McNally, R. J., Alpert, N. M., ThompSon, W. L., Rauch, S. L., Macklin, M. L., \& Pitman, R. K. (1997). Visual imagery and perception in posttraumatic stress disorder: A positron emission tomographic investigation. Archives of General Psychiatry, 54, 233-241.

* Shin, L. M., McNally, R. J., Kosslyn, S. M., Thompson, W. L., Rauch, S. L., Alpert, N. M., Metzger, L. J., Lasko, N. B., Orr, S. P., \& Pitman, R. K. (1999). Regional cerebral blood flow during script-driven imagery in childhood sexual abuse-related PTSD: A PET investigation. American Journal of Psychiatry, 156, 575-584.

Silberman,E. K., \& Weingartner,H. (1986). Hemispheric lateralization of functions related to emotion. Brain \& Cognition, 5, 322-353.

Simpson, J. R., Ongur, D., Akbudak, E., Conturo, T. E., Ollinger, J. M., SNyder, A. Z., Gusnard, D. A., \& Raichle, M. E. (2000), The emotional modulation of cognitive processing: An f MRI study. Journal of Cognitive Neuroscience, 12(Suppl. 2), 157-170.

Small, D. M., Zald, D. H., Jones-Gotman, M., Zatorre, R. J., Pardo, J. V., Frey, S., \& Petrides, M. (1999). Human cortical gustatory areas: A review of functional neuroimaging data. NeuroReport, 10, 7-14.

* Sprengelmeyer, R., Rausch, M., Eysel, U. T., \& Przuntek, H. (1998). Neural structures associated with recognition of facial expressions of basic emotions. Proceedings of the Royal Society of London: Series B, 265, 1927-1931.

Sprengelmeyer, R., Young, A. W., Calder, A. J., Karnat, A., Lange, H., Homberg, V., Perrett, D. I., \& Rowland, D. (1996). Loss of disgust: Perception of faces and emotions in Huntington's disease. Brain, 119, 1647-1665.

Sprengelmeyer, R., Young, A. W., Schroeder, U., Grossenbacher, P. G., Federlein, J., Büttner, T., \& Przuntek, H. (1999). Knowing no fear. Proceedings of the Royal Society of London: Series B, 266, 2451-2456.

Sprengelmeyer, R, Young, A. W., Sprengelmeyer, A., Calder, A. J., Rowland, D., Perrett, D., Homberg, V., \& Lange, H. (1997). Recognition of facial expressions: Selective impairment of specific emotions in Huntington's disease. Cognitive Neuropsychology, 14, 839-879.

*Strange, B. A., Henson, R. N., Friston, K. J., \& Dolan, R. J. (2000). Brain mechanisms for detecting perceptual, semantic, and emotional deviance. NeuroImage, 12, 425-433.

Tabert, M. H., Borod, J. C., Tang, C. Y., Lange, G., Wei, T. C., Johnson, R., Nusbaum, A. O., \& Buchsbaum, M. S. (2001). Differential amygdala activation during emotional decision and recognition memory tasks using unpleasant words: An fMRI study. Neuropsychologia, 39, 556-573

Talairach, J., \& Tournoux, P. (1988). Co-planar stereotaxic atlas of the human brain. New York: Thieme.

* Taylor, S. F., Liberzon, I., Fig, L. M., Decker, L. R., Minoshima, S., \& Koeppe, R. A. (1998). The effect of emotional content on visual recognition memory: A PET activation study. NeuroImage, $\mathbf{8}, 188$ 197.
* Taylor, S. F., Liberzon, I., \& Koeppe, R. A. (2000). The effect of graded aversive stimuli on limbic and visual activation. Neuropsychologia, 38, 1415-1425.

* Teasdale, J. D., Howard, R. J., Cox, S. G., Ha, Y., Brammer, M. J., Williams, S. C., \& Checkley, S. A. (1999). Functional MRI study of the cognitive generation of affect. American Journal of Psychiatry, 156, 209-215.

Tomkins, S. (1982). Affect theory. In K. R. Scherer \& P. Ekman (Eds.), Approaches to emotion (pp. 163-195). Hillsdale, NJ: Erlbaum.

* Vuilleumier,P., \& Schwartz, S. (2001). Beware and be aware: Capture of spatial attention by fear-related stimuli in neglect. NeuroReport, 12, 1119-1122.

Watson, D., Wiese, D., Vaidy a, J., \& Tellegen, A. (1999). The two general activation systems of affect: Structural findings, evolutionary considerations, and psychobiological evidence. Journal of Personality \& Social Psychology, 76, 820-838.

* Whalen, P. J., Bush, G., McNally, R. J., Wilhelm, S., McInerney, S. C., JeniKe, M. A., \& RAUCH, S. L. (1998). The emotional counting Stroop paradigm: A functional magnetic resonance imaging probe of the anterior cingulate affective division. Biological Psychiatry, 44, 1219-1228.

* Whalen, P. J., Shin, L. M., McInerney, S. C., Fischer, H., Wright, C. I., \& RaUCH, S. L. (2001). A functional MRI study of human amygdala responses to facial expressions of fear versus anger. Emotion, 1, 70-83.

* Williams, L. M., Phillips, M. L., Brammer, M. J., Skerrett, D., Lagopoulos, J., Rennie, C., Bahramali, H., Olivieri, G., David, A. S., Peduto, A., \& Gordon, E. (2001). Arousal dissociates amygdala and hippocampal fear responses: Evidence from simultaneous fMRI and skin conductance recording. NeuroImage, 14, 1070-1079.

* Zald, D. H., Lee, J. T., Fluegel, K. W., \& Pardo, J. V. (1998). Aversive gustatory stimulation activates limbic circuits in humans. Brain, 121, 1143-1154.

* ZALD, D. H., \& PARDO, J. V. (1997). Emotion, olfaction, and the human amygdala: Amygdala activation during aversive olfactory stimulation. Proceedings of the National Academy of Sciences, $\mathbf{9 4 ,}$ 4119-4124.

* Zalla, T., Koechlin, E., Pietrini, P., Basso, G., Aquino, P., Sirigu, A., \& Grafman, J. (2000). Differential amygdala responses to winning and losing: A functional magnetic resonance imaging study in humans. European Journal of Neuroscience, 12, 1764-1770.

* Zatorre, R. J., Jones-Gotman, M., \& Rouby, C. (2000). Neural mechanisms involved in odor pleasantness and intensity judgments. NeuroReport, 11, 2711-2716.

(Manuscript received March 26, 2003; revision accepted for publication August 12, 2003.) 